Joint trajectories of task value in multiple subject domains :

From both variable- and pattern-centered perspectives

\title{
Guo, Jiesi
}

2018-10-09

Guo , J , Wang , M-T, Ketonen , E E , Eccles , J S \& Salmela-Aro , K 2018 , ' Joint trajectories of task value in multiple subject domains : From both variable- and pattern-centered perspectives ', Contemporary Educational Psychology, vol. 55 , pp. 139-154 . https://doi.org/10.1016/j.cedpsych.2018.10.004

http://hdl.handle.net/10138/320150

https://doi.org/10.1016/j.cedpsych.2018.10.004

cc_by_nc_nd

acceptedVersion

Downloaded from Helda, University of Helsinki institutional repository.

This is an electronic reprint of the original article.

This reprint may differ from the original in pagination and typographic detail.

Please cite the original version. 


\section{Accepted Manuscript}

Joint Trajectories of Task Value in Multiple Subject Domains: From Both Variable- and Pattern-Centered Perspectives

Jiesi Guo, Ming-Te Wang, Elina E. Ketonen, Jacquelynne Sue Eccles, Katariina Salmela-Aro

PII: S0361-476X(18)30025-0

DOI: https://doi.org/10.1016/j.cedpsych.2018.10.004

Reference: YCEPS 1722

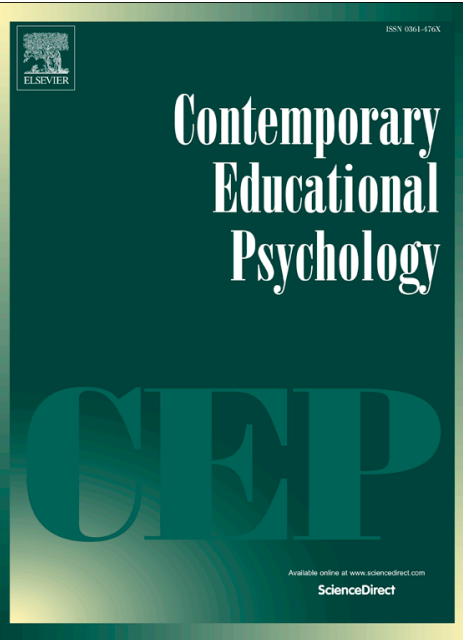

To appear in:

Contemporary Educational Psychology

Received Date:

13 January 2018

Revised Date:

3 October 2018

Accepted Date:

8 October 2018

Please cite this article as: Guo, J., Wang, M-T., Ketonen, E.E., Sue Eccles, J., Salmela-Aro, K., Joint Trajectories of Task Value in Multiple Subject Domains: From Both Variable- and Pattern-Centered Perspectives, Contemporary Educational Psychology (2018), doi: https://doi.org/10.1016/j.cedpsych.2018.10.004

This is a PDF file of an unedited manuscript that has been accepted for publication. As a service to our customers we are providing this early version of the manuscript. The manuscript will undergo copyediting, typesetting, and review of the resulting proof before it is published in its final form. Please note that during the production process errors may be discovered which could affect the content, and all legal disclaimers that apply to the journal pertain. 


\title{
Joint Trajectories of Task Value in Multiple Subject Domains: From Both Variable- and Pattern-Centered Perspectives
}

\author{
Jiesi Guo ${ }^{1}$, Ming-Te Wang ${ }^{2}$, Elina E. Ketonen ${ }^{3}$, Jacquelynne Sue Eccles ${ }^{4}$ \\ Katariina Salmela-Aro ${ }^{3}$ \\ ${ }^{1}$ Australian Catholic University (Australia) \\ ${ }^{2}$ University of Pittsburgh, Pittsburgh (USA) \\ ${ }^{3}$ University of Helsinki (Finland) \\ ${ }^{4}$ University of California-Irving, Irvine (USA)
}

Author Note. This study was supported by the Academy of Finland grant \#273872, \#308351, and \#307598 to Katariina Salmela-Aro."

Correspondence concerning this article should be addressed to Jiesi Guo, Institute for Positive Psychology and Education, Australian Catholic University, 25A Barker Road, Strathfield, NSW, Australia, 2135. Email: jiesiguo@gmail.com

Coauthor Contact:

Ming-Te Wang: mtwang@pitt.edu

Elina E. Ketonen: elina.e.ketonen@helsinki.fi

Jacquelynne Sue Eccles: jseccles@uci.edu

Katariina Salmela-Aro: katariina.salmela-aro@helsinki.fi 


\begin{abstract}
This study used variable- and pattern-centered approaches to better capture the impact of adolescents' joint developmental trajectories of subjective task values (STVs) in three domains (Finnish, math and science, and social subject) from grades 9 to 11 on science, technology, engineering, and mathematics (STEM) aspirations at four years postsecondary school and STEM participation at six years postsecondary school $(N=849$ Finnish youth; $52.1 \%$ female; $99 \%$ native Finnish). Results showed that while adolescents' average STVs in different domains remained stable, three differential joint STV trajectories emerged across domains. Individual changes of STVs in one domain shaped STVs in other domains to form unique relative STV hierarchies within subgroups that impacted long-term STEM aspirations and participation. Gender differences in STV trajectory profile distributions partially explained the overall underrepresentation of women in STEM fields. This study is among the first to incorporate multiple domains and explore how STVs fluctuate over time in both homogeneous and heterogeneous fashions. These findings underscore the importance of examining heterogeneity in motivational trajectories across domains.
\end{abstract}

Keywords: Expectancy-value theory, task values, gender gap, STEM, career choice 
Many talented and capable students are opting out of the science, technology, engineering, and mathematics (STEM) pipeline and women remain overall underrepresented in STEM fields (Miller, Eagly, \& Linn, 2015; Stoet \& Geary, 2018). These two issues represent an international phenomenon that has sparked considerable concern from policy makers and STEM professionals. Since elevated academic motivation in math and science during high school has been positively linked to persistent learning, better knowledge acquisition, and higher aspirations in STEM domains (e.g., Guo, Marsh, Parker, Morin, \& Yeung, 2015; Guo, Marsh, Parker, Morin, \& Dicke, 2017; Guo, Parker, Marsh, \& Morin, 2015), researchers have sought to understand how achievement motivation during adolescence contributes to a sustained trajectory of STEM participation (Wang \& Degol, 2013). Although studies have consistently demonstrated a uniform decline in students' academic motivation in math and science throughout adolescence (Wigfield, Tonks, \& Klauda, 2016), more recent studies have shown that students are likely to develop differential trajectories in these areas (e.g., Musu-Gillette, Wigfield, Harrin, \& Eccles, 2015; Wang, Chow, Degol, \& Eccles, 2017). For example, some students may experience declines in math and science motivation, whereas others experience a stable or increasing motivational trajectory during adolescence. These divergent trajectories have been differentially associated with academic performance, course selections, and career aspirations (e.g., Wang et al., 2017).

More importantly, the development of motivation in one subject domain seems to influence one's valuing of activities in other academic domains (Wang \& Degol, 2016). For instance, by evaluating one's academic strengths and weaknesses across different domains, a student can distinguish subjects in which they excel, which likely prompts an in-depth exploration of interests related to that academic domain. Simultaneously, this student would 
lower their interests in subject domains in which they hold a relatively low expectancy for success. The student's joint motivational trajectories across domains would form a relative intraindividual (i.e., cross-domain) hierarchy of motivation. Because choices of college major and career trajectory occur while adolescents are constructing this hierarchy, individual differences in the development of a relative motivation hierarchy are critical to understanding why youth select one career path over another.

Despite the call for examining relative motivation hierarchies across multiple academic domains, extant studies have yet to incorporate multiple subject domains, investigate individual differences in joint developmental changes, and link these variables to long-term educational and career pathways. Moreover, scant attention has been given to the difference between assuming heterogeneity based on a single study sample and identifying and recognizing between-subgroup heterogeneity, a distinction central to the study of individual and gender differences in career development. The use of both variable- and pattern-centered approaches may provide a more holistic picture of different motivational trajectories' impact on STEM career development while also helping to identify areas where interventions could be fruitful for increasing STEM participation, particularly for women.

In this study, we use an expectancy-value theoretical framework (EVT, Eccles, 2009) to investigate subjective task values (STVs) attached to various subject domains. First, we examine the average joint trajectories of STVs in three domains (i.e., Finnish, math/science, and social subjects) for all individuals from grades 9 to 11 using a variable-centered approach. Next, we shift to a between-subgroup heterogeneous perspective (i.e., pattern-centered approach) in which we hope to identify multiple trajectory groups with distinct joint developmental patterns of STVs across domains. We then link these trajectory patterns to STEM aspirations at four years 
postsecondary school and STEM participation at six years postsecondary school and explore gendered motivational trajectories and how they contribute to gender differences in STEM fields. Finally, we discuss the divergent predictive patterns between variable- and pattern-centered approaches. It should be noted that although self-concept (i.e., expectancies) trajectory also play an imperative role in differentiating individual's educational and occupational pathways, adding self-concept in multiple domains will be beyond our current statistical approaches and greatly increase the complexity of this study. Thus, we only focus on STVs in three domains in the present study due to complexity of our current statistical approaches.

\section{Development of Subjective Task Values based on Expectancy-Value Framework}

Eccles' EVT (2009), a major theoretical framework for studying achievement motivation, has been widely used when investigating both individual and gender differences in education and career trajectories (see Wang \& Degol, 2013, 2016 for reviews). EVT posits that achievementrelated choices (e.g., career selection) are linked to intellectual competencies and an array of psychological and socio-cultural factors. Subjective task values (STVs) are one of the major psychological components of EVT. STVs consist of intrinsic value (i.e., the personal enjoyment or liking of a task), utility value (i.e., the perceived usefulness of the task as related to fulfilling personal goals), attainment value (i.e., the perceived relevance of a task to one's sense of self, identity, and core personal values), and cost (i.e., the perceived negative aspects of making a specific choice). In addition, The relative STVs associated with subject domains have been found to influence education- and career-related choice behaviors more so than course grades (Eccles, 2009). Indeed, the process of career selection is inherently comparative: All options are assumed to be associated with costs, as one choice often eliminates other options (Eccles, 2009). For example, let us consider a student's decision to major in physics at college. Student is likely 
to select this major only if they place higher value on physics than they do on other majors. Thus, the student's relative STVs influence their educational and occupational decision-making .

Extant research using latent growth modelling (LGM) has indicated that students' STVs decline in each subject domain following elementary school and although specific trends vary somewhat across studies, these STVs become relatively stable during late adolescence (e.g., Dotterer, McHale, \& Crouter, 2009; Fredricks \& Eccles, 2002; Gottfried, Marcoulides, Gottfried, Oliver, \& Guerin, 2007; Petersen \& Hyde, 2017; Watt, 2004). Specifically, researchers in the U.S. found that on average, adolescents' STVs for verbal domains (e.g., language and reading) remained unchanged and those for math and science slightly declined (Fredricks \& Eccles, 2002; Gottfried et al., 2007; Jacobs, Lanza, Osgood, Eccles, \& Wigfield, 2002; Petersen \& Hyde, 2017). Watt (2004) looked at changes in an Australian sample and found that STVs in English and math declined to a very small extent during the high school transition. Furthermore, Dotterer et al. (2009) showed that American students' interest in reading, writing, math, language arts, and science declined over time although the decline decelerated during late adolescence.

There are two major explanations for the average declining STV trajectories across domains. Some have attributed these declines primarily to aspects of cognitive development. Children in the early elementary years tend to be quite optimistic about their abilities in different domains and have unrealistic expectations of how interesting these subjects are (Wigfield et al., 2016). As their cognitive skills develop and school environments change, academic performance and social comparison begin to shape the students' STVs (Wang et al., 2017). In an achievementoriented environment, students are likely to evaluate their abilities through social comparisons. In other words, they liken their self-perceived performance in a subject domain to that of their peers. Such comparisons undermine a student's self-perception of ability in that domain, 
particularly if the student is experiencing academic difficulties (Archambault, Eccles, \& Vida, 2010). To protect their self-esteem and self-worth, students may begin to devalue activities and subjects in which they flounder by concluding that those subjects are not interesting or that they do not fit their personal goals and identities (Fredricks \& Eccles, 2002).

Others attributed declining motivational trajectories to the mismatch between an adolescent's developmental needs and their school environment (Eccles et al., 1993). Students expect to have more autonomy and independence in learning during adolescence; however, opportunities to meet adolescents' needs in a school environment are limited because of the isolative structure of many high schools and the demands on teachers to manage large student loads, often resulting in the use of controlling classroom strategies and normative grading (Eccles et al., 1993). This mismatch contributes to many students' declining motivation between elementary and secondary school.

\section{Development of Academic STVs During High School Transition Using Pattern-Centered}

\section{Approaches}

While a tremendous body of research has used variable-centered approaches to focus on average trends of motivational change, the general decline pattern characterizes most, but not all, students (Archambault et al., 2010, Musu-Gillette et al., 2015; Wang et al., 2017). Recently, researchers have employed pattern-centered approaches (i.e., growth mixture modelling, GMM) to demonstrate that students evidence divergent motivational trajectories, especially during the high school years (e.g., Archambault et al., 2010, Musu-Gillette et al., 2015; Wang et al., 2017). In a longitudinal study, Archambault et al. (2010) tracked the development of literacy STVs across grades 1 through 12 . While seven trajectory groups were identified in which children all showed motivational decreases with different rates, three groups experienced some recovery 
during the high school years. Similarly, later inclining trajectory groups were identified in two other recent studies focusing on math and science STVs (see Musu-Gillette et al., 2015, Wang et al., 2017). In one of these studies, the later inclining trajectory group reported a decrease in science STVs across seventh to ninth grade, which was then followed by an increase during high school transition (Wang et al., 2017).

A developmental perspective may explain why multiple population subgroups with distinct trajectories emerge while also offering a theoretical rationale for the importance of tracking joint motivational trajectories across domains during the high school transition. From developmental science, we know that educational and occupational aspirations began to crystallize during high school (Eccles et al., 1993), resulting in students placing higher value on subject domains closely related to their chosen academic and/or occupational path. For example, a math-related career plan may promote one's perceived math utility (see Lauermann, Tsai, \& Eccles, 2017).

In addition, heterogeneous trajectories, including various increasing STV trajectories in different subgroups, may result from changes in cognitive ability and the school environment. On the one hand, the educational curriculum becomes more specialized and challenging in high school, making it difficult for students to succeed at all subject domains given the increasing demands on their time, energy, and effort. Starting in high school, students also have more freedom to choose the courses as well as the difficulty level of these courses and such autonomy may buffer against students' declining motivation in a particular domain (Wigfield et al., 2016; Wang et al., 2017). On the other hand, course selection depends upon relative (i.e., not absolute) STVs across different domains, which is closely related to domain comparisons within individual (Wang \& Degol, 2016). 
These within-individual domain comparisons are addressed through dimensional comparison theory (DCT). According to DCT, students evaluate their strengths and weaknesses by comparing their performances in one subject domain against their performance in other subject domains through contrasting and assimilating processes (Möller \& Marsh, 2013). Contrasting dimensional comparison processes predict that high aptitude in one domain leads to lower ability self-concept in other domains, whereas assimilating dimensional comparison processes characterized by high aptitude in one domain leads to higher self-concept in other domains. Students engage in contrasting or assimilating dimensional comparisons based on their beliefs as to whether their abilities in different domains are negatively or positively correlated (Möller \& Marsh, 2013). One of the critical assumptions of DCT is that perceived subject similarity corresponds to the verbal-math continuum of academic domains (Marsh, Byrne, \& Shavelson, 1988). Assimilation effects occur between subjects close to each other on the continuum (e.g., native and foreign language), whereas contrast effects are found to occur between subjects far from each other (e.g., language and math) (Guo et al., 2017; Marsh et al., 2015).

More recently, DCT has been used to connect dimensional comparison processes to broader affective and motivational consequences (Möller et al., 2015). For example, dimensional comparison processes were found to promote students' STVs in domains in which they excel and undermine STVs in domains that they perceive as dissimilar (Guo et al., 2017; Schurtz, Pfost, Nagengast, \& Artelt, 2014). In other words, dimensional comparisons are self-differentiation processes that help students develop a relative hierarchy of STVs across domains. These dimensional comparison processes become an asset to students as they move through changing academic settings and educational demands. In particular, when students start chossing their high 
school courses, the influence of dimensional comparison processes on students' STVs becomes even more dominant because it helps students to distinguish domains for which they could develop interests and preferences. Subsequently, motivation in different domains may act differently over time within different groups.

\section{Why Both Variable- and Pattern-Centered Approaches Are Needed to Study STV}

\section{Trajectories?}

Methodologically, both LCM (i.e., variable-centered approaches) and GMM (i.e., patterncentered approaches) assume that change over time is heterogenous within a population: "each individual is accorded his or her own personal trajectory" (Bauer, 2007, p. 776); however, these approaches have different assumptions as to how this heterogeneity is distributed. LCM assumes that the sample is drawn from a single population, in which the average and variance (i.e., heterogeneity) of students' initial level of STVs (intercept) and its relationship with time (slope) are estimated. A large variance in intercepts and slopes indicates heterogonous changes across the sample. When multiple subject domains are included (in multivariate LCM), relationships between intercepts and slopes across subject domains are also estimated. For example, where a student starts in one subject might relate to where he/she starts in another subject.

Although many studies (e.g., Jacobs et al., 2002; Petersen \& Hyde, 2017; Gottfried et al., 2007) have documented the average developmental change in motivation, two major research gaps need to be filled. First, relatively few researchers have examined how STV trajectories are associated with later educational and career-related choices. Gottfried, Marcoulides, Gottfried, and Oliver (2013) presented one of the few studies addressing this line of inquiry by linking the average trajectory in math intrinsic motivation to course accomplishment in later high school years. They revealed that a high initial level of math intrinsic motivation at age 9 , but not the 
trajectory slope contributed to greater involvement and persistence in advanced math courses.

Second, most motivational research has only examined one domain at a time (Jacobs et al., 2002;

Petersen \& Hyde, 2017; Watt, 2004). Thus, by using a LCM, we can explore how a

developmental trajectory in one domain is associated with trajectories in other domains as well as how trajectories in different domains interact to shape long-term educational and career choices.

On the other hand, GMM assumes that the sample is drawn from multiple population subgroups, characterized by qualitatively distinct patterns of change over time. GMM is an exploratory analysis that serve as an extension of the multiple-group growth model where the grouping variable is latent or unobserved (Grimm, Ram, \& Estabrook, 2017). Thus, the interpretation of the parameters in unobserved groups only provides circumstantial evidence of unseen groups (Grimm et al., 2017). Indeed, Bauer and Curran (2003) found that a GMM with multiple classes was almost universally favored, when longitudinal growth data is non-normal, even if the data is from a single population (considered typical of social science data). Other issues, such as incomplete sampling of a single population, measurement distortion, or nonlinear associations could also manifest as mixture of normal distributions, producing artificial groups in GMM (Bauer, 2007; Muthén, 2003). As such, GMM should be used when theory predicts the presence of a latent taxonomy consisting of qualitatively distinct groups.

According to EVT, a relative intraindividual (i.e., within-person, cross-domain) hierarchy of STVs matters more than between-person differences in the selection of a career pathway because of the numerous options from which to select a college major and career (Eccles, 2009). Theoretically, people in a subgroup that prioritizes math/science STVs over other domains are more likely to enter STEM fields, yet, little is known about how joint motivational trajectories 
across domains form a relative hierarchy of STVs during adolescence. For example, is there a subgroup that attaches increasing STVs to math while devaluing language to form relative high math/science STVs in high school? To fill this gap in existing research, we employ GMM to look into joint motivational changes of STVs by incorporating three subject domains: math/science, Finnish, and social subjects. In the Finnish educational curriculum, social subjects mainly include history and civics, thus representing a more content-based domain as compared to math and verbal domains (see below for a detailed description about the educational context in Finland). The inclusion of these three domains represents a broad spectrum of the verbal-math continuum (Marsh et al., 1988; see Appendix 1 for hypothesized continuum), hence allowing for the exploration of how STVs contrast and interact with each other across domains to shape a relative hierarchy.

\section{Gendered Trajectories and Pathways to STEM Careers}

Previous EVT research has demonstrated that males are likely to perceive math and science as more important, useful, and enjoyable than females, whereas females are likely to have higher STVs for language and social subjects throughout elementary and secondary school (e.g., Jacobs et al., 2002; Petersen \& Hyde, 2017; Watt, 2004; Wigfield et al., 2016). These studies have documented that gender gaps in math STVs appear to be relatively stable or even slightly smaller during high school. Importantly, these gender differences have been useful when explaining women's underrepresentation in STEM fields (e.g., Guo, Eccles, Sortheix, \& Salmela-Aro, 2018; Wang \& Degol, 2016). For example, Chow et al. (2012) found that eleventh grade males were more likely than females to fall into a group that values math and science more than other subject areas, hence partially explaining gender disparities in the desire for STEM careers. By capturing gendered joint trajectories of STVs across multiple domains and examining 
their contributions to gender differences in STEM participation during post-high school transition, we hope to achieve a deeper understanding of how motivational-developmental processes characterized by different groups of students shape gendered pathways to STEM careers.

\section{The Present Study}

Drawing on EVT (Eccles, 2009), the present study modeled the joint trajectories of students' STVs in different subject domains during high school transition (i.e., grades 9 through 11) and examined how these trajectories were related to gender, STEM aspirations, and the engagement in STEM careers four to six years after post-high school transition. Importantly, this study is among the first to explore how STVs in multiple subject domains fluctuate over time, thereby enabling us to construct a more nuanced portrait of the developmental course of adolescents' STVs across the middle and high school years. In this study, we pursued four objectives. First, we examined the average, joint developmental trajectory of STVs in different subject domains (i.e., Finnish, math/science, and social subjects) using multivariate LCM. Second, we studied joint trajectories of STVs across domains by exploring whether different groups of students followed distinct trajectories of STVs using GMM. Third, we linked these trajectory patterns to STEM aspirations and participation, and finally, we explored gendered motivational trajectories leading to STEM fields. We organized our hypotheses based on both variable- and pattern-centered approaches (see Table 1).

\section{Methods}

\section{Participants and Procedure}

Participants. The data set was part of the larger Finnish Educational Transition Studies (FinEdu), an ongoing longitudinal study tracking a cohort of ninth grade students from all 
comprehensive schools (upper level, grades 7 to 9) in a city in central Finland since 2004. We first examined the developmental trajectories of students' STVs from ninth grade to eleventh grade. At the first assessment (ninth grade), the sample contained 682 students $\left(M_{\text {age }}=16.0\right.$ years, $S D=.65)$. In each subsequent year, the study not only tracked the students who had participated in previous assessment, but it also included students who had enrolled in FinEdu classrooms after the initial assessment, resulting in sample size of 734 (tenth grade, $M_{\text {age }}=17.1$, $S D=.68)$ and 625 (eleventh grade, $M_{\text {age }}=18.1$ years, $S D=.63$ ). Due to this sampling design, a portion of the sample had missing data for at least one of the measurement waves. Across the three waves, 54\% participated in all three measurement waves, and $31 \%$ and $15 \%$ took part in the two or one of the assessments, respectively. In total, 849 participants were included in our analysis of motivational trajectories (from ninth grade to eleventh grade). We then linked the individuals' motivational trajectories to post-high school variables in 2011 (Wave 4, four years post-high school, $N=577, M_{\text {age }}=23.0$ years, $S D=.61$ ) and 2013 (Wave 5, six years post-high school, $N=535, M_{\text {age }}=25.4$ years, $\left.S D=.60\right)$. Not surprisingly, the sample attrition was relatively large for post-high school variables, as they were collected 6-9 years after Wave 1 (32\% for STEM career aspirations and 37\% for actual studying or working in STEM fields).

Procedure. This study used self-report questionnaire data collected from the participants. The questionnaires were administered to the students in their high school classrooms under the supervision of a teacher. Post-high school questionnaires and instructions were sent to participants' homes. Females comprised $52.1 \%$ of the sample $(N=849)$. Nearly all participants (99\%) reported Finnish as their first language, and this pattern aligned well with the ethnic composition of the population in Central Finland.

\section{Educational Context}


High school transition is a critical stage for Finnish adolescents. In the Finnish educational system, students transition from comprehensive school to high school in $10^{\text {th }}$ grade (i.e., 15 or 16 years old), which also happens to be their first main school transition. Upon transitioning to high school, Finnish students choose to pursue an academic or vocational track. As this study aimed to examine motivational development across academic domains and subsequent educational and occupational choices in STEM fields, we focused on the students in the academic track. Furthermore, the Finnish educational system implements course-by-course tracking within schools, but it does not use academic tracking between schools in high school. Students are relatively free to choose difficulty levels or numbers of classes in many subjects, thus triggering dimensional comparison processes and developing relative STVs. As part of their preparation for University study, Finnish students on the academic track strive to be successful and choose more challenging schoolwork; therefore, the Finnish high school environment is oriented toward social comparison and competition among peers (Salmela-Aro \& Tynkkynen, 2012). Interestingly, Finnish students completing the academic track have a higher-than-average age at the time of their graduation from university, with the age of university completion ranging between 25 and 28 (Sortheix et al., 2015). The main reason for this late graduation age is the competitive university entry system in Finland. Many young people take multiple gap-years to pass university entrance examinations so that they can get into their desired majors (Sortheix et al., 2015). These key characteristics of the Finnish educational system emphasize the importance of tracking individual and gender differences in motivational development during high school transition. By focusing on high school transition, we were able to leverage efforts to support the development of STEM-related knowledge and task values.

\section{Measures}


Subjective task values (STVs). STVs for the three school subject domains, including (a) Finnish, (b) math and science, and (c) social subjects ${ }^{1}$ were measured by the STV scale (Eccles et al., 1983). The scale included three items that asked the participant to assess the interest, importance, and usefulness of each subject domain via the question: "How interesting/important/useful do you think each of the following subjects is?" All items were coded on a seven-point Likert scale, with one indicating "not at all" and seven indicating "very much". The domain-specific latent STV constructs demonstrated satisfactory reliability across time (Cronbach's $\alpha=.81-.85$; also see Chow et al., 2012).

STEM aspirations and participation. Participants' STEM occupational aspirations were measured at Wave 4 (i.e., four years after post-high school transition) based on the responses to the question: "What is your field of the desired occupation?" Because of the long post-high school transition, only $21.8 \%$ of participants had entered the workforce at Wave 4 . When analyzing these responses, we operationalized occupations into two categories. Category 1 encapsulated all non-STEM occupations, including careers in the fine arts, literature, business, education (except for math and science teachers), and social subjects (e.g., history, political science). Category 2 contained all STEM-related occupations, such as careers in mathematics, engineering, computer science, life science, medical science, physical science, and as math or science teachers $^{2}$ (see Wang, Degol, \& Ye, 2015). We also used these categories when assessing participants' actual STEM participation (i.e., studying or working in STEM fields) at Wave 5

\footnotetext{
${ }^{1}$ To avoid confusion, participants were given specific subject examples (e.g., history, civics) when asked about their STVs in social subjects. It should also be noted that the label "social subjects" is commonly used in Finland's education system.

${ }^{2}$ In this study STEM occupations were defined based on the skills and training required. Given that in Finland math and science teachers require master's degrees specializing in math or a specific science domain, we categorized this occupation as part of the STEM careers, which is what has been defined in the U.S.( e.g., Miller \& Kimmel, 2012; Wang et al., 2015).
} 
(i.e., seven years post-high school). For those who had not yet entered the work force, "What is your field of study at the moment?" was used, while for the $41.0 \%$ of participants who had entered the workforce by Wave 5, "What is your professional field at the moment?" was employed ${ }^{3}$.

\section{Covariates}

Grade point average (GPA). In Finland, all students are provided with an overall GPA for all the courses they attend in each academic year. GPA was calculated on a scale ranging from 4 to 10, with four indicating poor performance and ten indicating excellent performance. Participants were asked to report their GPAs from the previous year at each wave. Thus, GPAs from grades eight through ten were treated as time-varying covariates in this study.

Matriculation results in Finnish and math. We also included Finnish and math matriculation examination results, obtained from school records, in our analysis. We used these examination results in particular due to the high number of participants taking them: All candidates took the compulsory Finnish examination, while approximately $80 \%$ of participants opted to take math as one of their matriculation tests (Sortheix et al., 2015). As we were interested in STEM majors and careers, we controlled for the effect of math and Finnish achievement in our models.

Demographic factors. We included gender and family socioeconomic status (SES) of the participants as covariates in our analysis. Gender was coded as 0 (females) or 1 (males), while family SES was indicated by parents' occupations as reported at grade 9. Each parent's occupation was first coded; per the classification of socio-economic groups issued by Statistics

\footnotetext{
${ }^{3} 65 \%$ of participants who were still studying in university answered both questions. Among those, approximately $80 \%$ of them used exactly the same answer for both questions and the rest of them just slightly changed wording, indicating the high reliability of combining these two questions in the subsequent analysis.
} 
Finland (1989). We then further coded the data as 1 (unsalaried position), 2 (blue collar), 3 (lower white collar), and 4 (upper white collar). If both parents were working, the higher SES of either parent was used as the indicator for family SES.

\section{Data Analysis}

Missing data analysis. We explored potential missing data mechanisms by creating an early attrition group (i.e., participants who did not engage in all three measurement waves during the high school years) and a late attrition group (i.e., participants who left the study during posthigh school transition). We then conducted a series of $t$-tests to examine mean differences by attrition groups for both demographic variables and variables used in the analyses. We found that there were no differences between the early attrition group and the group with full data. However, males were more likely to drop out of the study than females during the post-high school transition $(t=4.32, d f=648.71, p<.001)$; and participants with lower GPAs at grade 11 $(S D=.40)$ were also more likely to drop out of the study during the transition $(t=2.34, d f=$ $470.99, p<.001)$. Missing data was not associated with STVs when compared between the early and late attrition groups and the group with full data. Full Information Maximum Likelihood (FIML) estimation was used to cope with missing data within STEM framework (Enders, 2010). Gender and GPA at grade 11 served as auxiliary variables in data analyses (i.e., confirmatory factor analysis [CFA], LCM, and GMM).

Table 2 provides descriptive statistics and intercorrelations for all variables. A longitudinal measurement invariance test across the three data-collection waves was conducted to verify the factor structure of STVs. We found empirical support for strict measurement invariance (i.e., invariant loadings, intercepts, and uniquenesses invariances) on the three domain-specific STVs across occasions (see Appendix 2 for the test of longitudinal measurement 
invariance). To facilitate interpretation of the latent means in LGM and GMM, we reparametrized the model using a nonarbitrary method to identify and set the scale of latent variables. This method allowed for estimating latent means in a nonarbitrary metric that reflects the metric of the indicators measured. As such, results could be interpreted according to the original 7-point Likert scale (see Appendix 8 for more details). We then used multiple process LCM and GMM to examine developmental trajectories of STVs All models were conducted with Mplus 7.13 using the robust maximum likelihood estimator (see Appendix 8 for detailed the model-building process and annotated Mplus syntaxes).

To test the first hypothesis, we examined the joint linear trajectories of the three STVs over time using multivariate LCM. Multivariate LCM focuses solely on between-person variability in the initial levels (intercepts) and rates of change (slopes) across multiple constructs of interest as well as between-person linear relations among these intercepts and slopes. This joint developmental model allowed us to simultaneously test the developmental course of the three STVs from grades 9 to 11. Subsequently, the three STVs' change parameters (intercepts and slopes) prediction of STEM outcomes was assessed while controlling for gender, SES, and matriculation scores.

To test the second hypothesis, GMM, a pattern-centered approach, was conducted to classify the participants into subgroups that evidenced different patterns of the joint trajectories of the three STVs over time. GMM is specifically designed to explain developmental heterogeneity by separating a general population into latent classes of participants presenting qualitatively and quantitatively distinct trajectories of change over time (Muthén, 2001). Given the complexity and heavy computation required by GMM, it is often impossible in practice to implement a fully latent approach to its estimation (Meyer \& Morin, 2016). Therefore, we relied 
on factor scores saved from preliminary measurement models (Morin \& Marsh, 2015). Factor scores provide a partial implicit control for measurement errors and preserve the nature of the underlying measurement structure better than scale scores. To ensure comparability in the STV measures across three waves, factor scores were saved from a model of strict measurement invariance.

Several indicators were used to select the optimal number of profiles (groups): the Akaike Information Criterion (AIC), the Consistent AIC (CAIC), the Bayesian information criterion (BIC), and the sample-adjusted BIC (saBIC). Lower values on these indicators suggest a better-fitting model. To further secure our decision in selecting the best model, we used the adjusted likelihood ratio test (LMR-LRT) and the bootstrap likelihood ratio test (BLRT) (Lo, Mendell, \& Rubin, 2001). Nonsignificant LMR-LRT and BLRT tests indicate that a model with k-1 profile model would provide a better fit compared to a k profile model. Finally, we relied on the Entropy Index to summarize classification accuracy (Lubke \& Muthén, 2007). The entropy varies from 0 to 1 , with higher values indicating fewer classification errors. While there appears to be no definitive criteria for determining optimal numbers of latent classes when estimating GMM models, researchers have recommended the use of multiple statistical indices, along with conceptual considerations and interpretability of the latent groups (Morin \& Marsh, 2015).

Based on the GMM results, we conducted a series of regressions to explore how STV profile memberships predicted STEM outcomes while controlling for gender, SES, and matriculation scores. Mixture models in Mplus provide class membership probabilities for each individual. Rather than using an 'all-or-none' approach of assigning class membership to participants based on the highest probability for one of the profiles, we employed each individual's estimated probability of membership for each class as sampling probabilities (i.e., 
CPROB1-CPROB3 in SAVEDATA of Mplus output) to create 25 imputations of class membership (Sahdra et al., 2017, see Appendix 3). Given that FIML was not able to cope with missing data on binary outcomes (i.e., STEM aspiration and participations) in Mplus, we instead used a multiple imputation approach in which all other variables used in the current study were included as covariates. We imputed 25 data points and merged them with another set of 25 imputed data points for class membership for subsequent analyses. All data analyses were run separately, and the results were aggregated appropriately in order to obtain unbiased estimates (Rubin, 1987). Thus, our approach accounted for classification uncertainty in the latent class membership and allowed for the testing of mediation effects for gender.

\section{Results}

\section{Variable-centered Approach}

Joint Trajectories of STVs in the three domains. To examine the joint trajectories of STVs across the three waves of data, we first specified an unconditional multivariate LCM model that simultaneously considered the three subject domains while including gender, SES, and timevarying GPAs as auxiliary variables. Note that the LCM model was built on the strict measurement invariance model. In other words, with strict invariance constraints imposed on the first-order measurement model, task value trajectories in the three subject domains were modeled as second-order latent factors in the LCM. Compared to the strict measurement invariance model $\left(\mathrm{CFA}, \chi^{2}=670, d f=303\right.$, comparative fit index $[\mathrm{CFI}]=.960$, the Tucker-Lewis index [TLI] $=.954$; the root mean square error of approximation $[\mathrm{RMSEA}]=.038$, see Appendix 2 ), the fit of the full LCM model slightly decreased but was still reasonably good $\left(\chi^{2}=819, d f=321\right.$, CFI $=.946, \mathrm{TLI}=.941 ; \mathrm{RMSEA}=.043)$. The reason of the decreased model fit may be due to some trivial residual covariances between task value items and second-order latent (intercept and slop) 
factors. However, for the sake of parsimony, we didn't explore and include those trivial residual covariances into the model given that the LCM fit the data relatively well. Mean levels of STVs in the three subjects at grade 9 were all significant (see Figure 1 for estimated averaged trajectories). As expected (H1a), STVs in math and science decreased over time to a small extent (slope $=-.07$, while STVs in social subjects and Finnish remained relatively stable. The conditional multivariate LCM model controlling for gender, SES, and time-varying GPAs provide the same model fits $\left(\chi^{2}=1039, d f=363, \mathrm{CFI}=.940, \mathrm{TLI}=.920, \mathrm{RMSEA}=.047\right)$ and a similar pattern of results as the unconditional model (see Table 3).

Table 4 lists the variances and correlations among the initial levels (intercepts) and rates of change (slopes) in relation to three domain-specific STVs (see Appendix 4 for more details). The intercepts of all STVs were positively and significantly correlated with each other. Specifically, the intercept of social subjects STVs was more closely related to that of Finnish STVs $(r=.63)$ than of math and science STVs $(r=.47)$, indicating that students were more able to distinguish STVs between Finnish and math/science at grade 9. Correlations among STVs in the three domains were substantially smaller at grade 11 . For instance, social subjects STVs were not significantly related to math and science STVs $(r=.10$, see Table 2$)$. These findings imply that students were more likely to develop divergent STV trajectories across different domains during high school. Similar patterns were found for the three slopes, but correlations were considerably weaker. Correlations between the intercepts and slopes across domains were either non-significant or carried a slightly negative valence. The significant between-person variability (variances) of the slopes across subjects indicated that the individual growth trajectories substantially differed in their steepness. 
Effects of the trajectories on STEM outcomes. Given that simultaneously testing effects of latent intercepts and slopes in all three domains on outcomes requires heavy computational burden in the LCM framework, we generated factor scores of intercepts and slopes and tested how they predicted STEM aspirations and careers using logistic regression. As seen in Table 5, all significant effects were found in the intercepts but not the slopes after controlling for gender, SES, and matriculation results in Finnish and math. As expected (H1b), students who had high initial levels of STVs in math and science but low initial levels in Finnish at grade 9 were more likely to aspire to and select STEM careers. Specifically, Odds Ratios $(O R)$ indicated that for each one $S D$ increase in math and science STVs, the odds of aspiring to and actually entering a STEM (versus non-STEM) field increased by a factor of 1.63 and 1.60, respectively.

Gender effects. As hypothesized (H1c), males had significantly higher levels of STVs in math and science than females, while females had higher STVs in Finnish and social subjects (see Table 3). Both genders evidenced similar STV trajectories across domains; however, faster declining math and science STVs among females resulted in a slightly larger gender gap. Hierarchical regression analyses revealed that the direct gender effects on STEM aspirations and participation were substantially reduced when initial levels of STVs were included in the model. Here, we calculated the magnitude of the relative indirect effects of gender, which can be loosely interpreted as the percentage reduction in the regression coefficients of gender between STEP 1 and STEP 2 (see Table 5, Huang, Sivaganesan, Succop, \& Goodman, 2004; Wang et al., 2015). Specifically, the initial levels of STVs explained $1-1.20 / 1.52=21 \%$ of gender differences in aspiring to entering STEM versus non-STEM fields and 30\% of gender differences in actual entry into STEM fields (comparing STEP1 to STEP2, see Table 5). As expected, gender 
differences in initial levels of STVs at grade 9 partially mediated gender disparities in STEM fields.

\section{Pattern-centered Approach to STV Trajectories}

Class enumeration. Given that unconditional and conditional LCM demonstrated a similar pattern of STV trajectories, we opted to use unconditional GMM models ${ }^{4}$. The values for AIC, BIC, CAIC, and SABIC for the one- to six-profile solutions continued to decrease with the addition of profiles (see Table 6). While the two to six profile solutions had a significant BLRT, LMR-LRT became non-significant after three-profile solutions. Moreover, the three profiles had reasonable sample sizes $(N=161-408)$ and the latent profile probabilities for the most likely latent class assignment of the three-type solution were satisfactory (see Table 7), resulting in an acceptable entropy value of .786. Ultimately, a three-profile solution showed good model fit and separation between the classes. The examination also revealed that adding a fourth profile resulted in the division of an existing profile into two distinct profiles differing only quantitatively from one another (See Appendix 5 for more details).

Given that most applications of mixture modelling are exploratory and results might not generalize beyond the sample under investigation, we used a newly developed cross-validation approach $-k$-fold cross-validation approach (Grimm et al., 2017) to further confirm the solution of model selection and thus enhance the replicability of our findings. Specifically, we conducted

\footnotetext{
${ }^{4}$ The focus of this study was to examine gender differences in distributions of the joint STVs trajectory profiles and explain how these patterns affect gender imbalance in STEM participation (as opposed to exploring whether different groups of students followed distinct trajectories of STVs while controlling for gender). Methodologically, adding covariates to the GMM generally hurt class recovery (i.e., participants were more accurately classified), except where the latent classes underlying the growth trajectories and covariates were strongly associated (Stegmann \& Grimm, 2018). In this study, the latent trajectory classes (based on three-profile solution) were only weakly associated with GPAs ( $R^{2}=3 \%-4 \%$ by ANOVA) and not associated with SES $\left(R^{2}<.01 \%\right)$. As such, we used the more parsimonious model (i.e., the unconditional GMM).
} 
5-, 10-, and 100-fold cross-validation for the GMM with one through six classes. For 5-fold cross-validation, each model (e.g., three-class GMM) was estimated five times to different partitions of the data ( $80 \%$ of the data each time), the results (i.e., parameter estimates as fixed values) were applied to the kth partition (20\% of the sample), and the -2 log likelihood (-2LL) for this model was saved. Similarly, for 10-/100-fold cross-validation, each model was estimated $10 / 100$ times $(90 \% / 99 \%$ of the data each time) and the results were applied to the remaining $10 \% / 1 \%$ of the sample (see Grimm et al., 2017 for more details).

Figure 2 illustrates the cross-validation results (the Mean and standard error $[S E]$ of the 2LL). Informed by Grimm et al.'s (2017, see p. 253 for details) suggestions on model selection, we started evaluating the one-class model, finding that the two-class model Mean of crossvalidated $-2 L L$ was outside of one $S E$ of the one-class model Mean. In addition, the three-class model Mean was outside of one $S E$ of the two-class model, indicating that the three-class model fit better than the one- and two-class models. The four-class model Mean was within one $S E$ of the three-class model, indicating the three-class model should be preferred in terms of parsimony. We also worked through cross-validation results beginning with the best fitting model (i.e., the six-class model). The five-class model Mean was within one $S E$ of the six-class Mean, and the four-class Mean was within one $S E$ of the five-class Mean. These results suggested that the fourth-class model fit similarly to the six- and five-class models. Again, the four-class model did not perform better than the three-class model in terms of model fit; thus, the three-class model was used.

It should be noted that means, variances and covariances, and residuals of the latent trajectory parameters (intercepts and slopes) across the three domain-specific STVs (i.e., Finnish, math and science, social subjects) were freely estimated in all classes, following the strategy of 
GMM estimation recommended by Diallo, Morin, and Lu (2016). We further compared these freely estimated GMMs with those placing constraints either on variances and covariances or on variances, covariances and residuals. Results showed the freely estimated GMMs were favored in terms of model fit across different class solutions (see Appendix 6 for more details).

Class descriptions. Three distinct profiles were consistent with our expectations $(\mathrm{H} 2 \mathrm{a})$; thus, they were retained as our final solution classes. The most probable proportion of individuals within the sample from class 1 was approximately $48 \%$ (see Figure 3 for estimated average trajectories across classes and Appendix 7 for observed individual trajectories). This class represented those students who showed high initial levels of STVs in all three domains (intercepts ranged from 5.19 to 5.31, see Table 8) but experienced declining trajectories in all three domains over time (slopes: ranged from -.12 to -.04). Therefore, Class 1 was labeled the High but Decreasing All Subjects trajectory. The most probable proportion from Class 2 was approximately 33\%. Students in this class had low levels of STVs in all three domains (intercepts ranged from 4.22 to 4.47 ), an increase in math and science STVs over time (slope $=.08$ ) and stable trajectories in Finnish and social subjects (i.e., nonsignificant slope). Thus, we labeled Class 2 the Low but Increasing Math and Science trajectory. The most probable proportion from Class 3 was approximately $19 \%$ and this class was the most distinctive. Students in this class reported initially high STVs in Finnish and social subjects (intercepts $=5.52$ and 5.19, respectively), but relatively low STVs in math and science (intercepts $=4.47$ ). Interestingly, the developmental trajectories were substantially different across domains: Students' Finnish STVs increased over time (slope $=.21$ ), their STVs in math and science declined (slope $=-.18$ ), and their STVs in social subjects remained stable. We labelled Class 3 the High and Increasing Finnish trajectory. 
Effects of the trajectory profiles on STEM outcomes. Logistic regression was conducted to examine how trajectory profile memberships predicted STEM aspirations and careers. We report odds ratios $(O R)$, which reflect the change in likelihood of entering STEM versus non-STEM fields associated with people being in a target work value profile versus a comparison profile. For example, an OR of 3 suggests that individuals with a particular work value profile are three times more likely to enter STEM over non-STEM fields than a comparison profile. Profile membership significantly predicted STEM outcomes (see Table 9). As expected (H2a; see Table 1), students in the Low but Increasing Math and Science trajectory were 1.86 times more likely to aspire to STEM careers and 2.59 times more likely to enter STEM careers, respectively, as compared to those in the High and Increasing Finnish trajectory (see STEP 2 in Table 9). Similarly, students in the Low but Increasing Math and Science trajectory were 2.10 and 2.72 times more likely to aspire to and enter STEM careers, respectively, as compared to those in the High but Decreasing All Subjects trajectory. Students from the High but Decreasing All Subjects and High and Increasing Finnish trajectories were associated with a similar likelihood of having STEM aspirations $(O R=1.13)$ or joining STEM fields $(O R=1.16)$.

Given that the initial level of STVs had significant effects on differentiating individual and gender differences in STEM participations in LCM (see Table 5), we further explored whether within-person shape of joint developmental trajectories could predict STEM outcomes above-and-beyond the between-person differences in the initial level of STVs. The predictive power of trajectory profile memberships were similar after controlling for the effects of each individual's initial STVs levels in the three target subjects at grade 9 (see STEP 3 in Table 9). 
Gender effects. As hypothesized $(\mathrm{H} 2 \mathrm{c})$, there were gender differences in the trajectory profiles. Note that gender distribution in this sample was almost even (males $=52.1 \%$ ). Table 10 shows that males were over-represented in the Low but Increasing Math and Science trajectory (66\%); females were over-represented in the High and Increasing Finnish trajectory (69\%); and the gender distribution was relatively even for the High but Decreasing All Subjects trajectory $($ males $=51 \%)$. Hierarchical regression analyses revealed that the direct effect of gender on STEM outcomes was substantially reduced when including the trajectory profiles distributed differently by gender. The proportions of the gender effects on STEM aspirations and participation mediated by trajectory profiles were $29 \%$ and $36 \%$, respectively (comparing STEP 1 to STEP2 in Table 9). Results also indicated that more proportions of gender differences in STEM outcomes were explained while further including initial levels of the STVs at grade 9 in the GMM model (STEP3). In summary, gender differences in profile distributions partially explained gendered pathways to STEM fields.

\section{Discussion}

This study integrated variable- and pattern-centered approaches to examine how individual and gender differences in joint motivational trajectories across three subject domains influenced career development during high school transition. While adolescents' STVs in different domains remained stable (in Finnish and social subjects domains) or slightly declined (in math and science domains) on average, we identified three differential trajectory patterns of STV change over time, suggesting that trajectories in multiple domains shape each other. Additionally, between-person differences in STVs at ninth grade and within-person heterogeneous patterns (i.e., trajectory groups) of STVs were substantially associated with posthigh school STEM aspirations and participation. Finally, differential motivational developments 
of males and females across different subject domains play a vital role in contributing to gendered career choices and gender disparities in STEM fields.

\section{Between-Person Differences in STV Trajectories}

This study extends prior research on motivational trajectories by considering the multidimensionality of students' STVs. The medium sizes of correlations among average initial levels of STVs across the three domains indicate that students do indeed distinguish STVs in different domains. The correlations between growth rates of the three STVs were positive but substantially small, suggesting that motivating students to value a domain may promote motivation in learning other domains, while devaluing activities in one domain may have negative effects on other domains. However, this finding should not be over-interpreted given such small effect sizes ( $d s=.10$ to .16$)$. Furthermore, this study is among the first to investigate how initial levels of STVs are related to growth rates across domains. Small negative or nonsignificant correlations indicate a slight compensatory effect: Grade 9 students who started with lower achievement motivation improved at a slightly faster rate (or diminished at a slightly slower rate) than those who started with higher motivation, resulting in a slight narrowing of the motivation gap. This finding is consistent with recent studies on academic achievement growth (e.g., Davis-Kean \& Jager, 2014; Mok, Mclnerney, Zhu, \& Or, 2014) but the underlying mechanisms behind this compensatory effect remain unknown. One possible explanation is that students with poorer initial performance and motivation may be likely to receive more instructional attention by teachers in school and by parents at home, particularly in secondary schools (Tan \& Yates, 2011).

While STV trends in Finnish, math/science, and social subjects seem to be stable or slightly declining over time, significant variances of growth rates indicated notable heterogeneity 
in individual growth curves. The small correlations among slopes supplement this finding, suggesting that students may experience differential patterns of development across different domains over time. Accordingly, our findings provide strong support for employing patterncentered approaches when trying to understand the within-person motivational dynamics in different learning domains.

\section{Subgroups with Distinct STV Trajectories}

We were able to identify three distinct STV trajectories: High but Decreasing All Subjects (48\%), Low but Increasing Math and Science (33\%), and High but Increasing Finnish (19\%). In line with our expectations, the High but Decreasing All Subjects trajectory consisted of a relatively large number of students who experienced continuous declines in all three subject domains. This pattern could be considered the normative developmental course of academic motivation for males and females adolescents as explained by social comparison processes and incongruence between their developmental needs and the school environment during the school transition (Eccles et al., 1993). Specifically, this group experienced a steeper decline in math and science STVs than in Finnish and social subjects. Indeed, the math and science contents in high school become abstract and require different forms of reasoning, which may make it harder for students to see the utility value of and be interested in math and science (Petersen \& Hyde, 2017). To protect the perceptions of their math and science ability, students may justify not pursuing advanced math and science courses by perceiving them as less useful and interesting. More importantly, different declining rates of the three domains formed a relative hierarchy of STVs where math and science were rated as the least important, thereby moving students away from STEM fields. 
Consistent with previous research (Archambault et al., 2010; Wang et al., 2017), we found two groups where students evidenced STV increases in Finnish or math/science during high school transition. This finding could be due to the students' autonomy to choose different levels of coursework and the self-differentiation process. Indeed, these two trajectory groups demonstrated how motivational developments in different domains influence each other through within-person dimensional comparison processes to evidence opposite patterns of development over time. Because of high perceived dissimilarity between verbal and mathematical domains (Marsh, 2007), a motivation growth in Finnish leads to a relative decline in math and science and vice versa (i.e., a contrasting effect). Motivational changes in social subjects are slightly close to those in Finnish across different trajectory groups, given that both domains are likely to be perceived as similar (i.e., an assimilating effect).

Interestingly, students in the Low but Increasing Math and Science trajectory had lower math and science STVs at grade 9 than those in the other two trajectory patterns. This finding raises the question of why students with lower STVs in math and science at the onset of high school experienced STV increases throughout high school (see Table 4). Potential underlying motivational mechanisms leading to STV increases may be the relative intra-individual hierarchy of STVs across domains and dimensional comparison processes. When compared to other domains, students in the Low but Increasing Math and Science trajectory placed the highest value on math and science at grade 9. This relative priority pattern of STVs may have helped these students select coursework and attribute more time and energy to the classes and activities that interested them and fit closely with their personal goals (Guo et al., 2015, 2017). Consequently, these students may place more academic STVs on math and science than on other subjects (Wigfield et al., 2016). In contrast, students in the High and Increasing Finnish group 
placed even higher value on Finnish and social subjects than on math and science at grade 9, which may have directed them away from math and science classes and activities, subsequently decreasing their perceived value of this domain. However, the role that the relative hierarchy of STVs plays in motivational development is less salient for the High but Decreasing All Subjects group where the three domains were rated similarly.

\section{Linking STV trajectories to STEM outcomes}

We not only detected between- and within-person patterns of STV trajectories, but we also found differential associations with post-high school STEM aspirations and participation. Interestingly, the strong effects of the trajectory profile groups remained while controlling for the students' initial levels of STVs. Although between-person differences in STVs (e.g., high math and science STV, low Finnish and social subjects STVs) at grade 9 appeared to discriminate between individuals who aspire towards and choose occupations in STEM versus non-STEM fields, the relative within-person hierarchy of STVs, coupled with differential developmental patterns, also played an important role in these choice behaviors. Indeed, students from the High but Decreasing All Subjects trajectory consistently held higher math and science STVs over time than those from the Low but Increasing Math and Science trajectory, but they still opted out of the STEM pipeline. While students from the High but Decreasing All Subject and High but Increasing Finnish trajectories had considerably different motivation experiences across domains, particularly at grade 11 (Wave 3), the similar relative priority patterns with decreasing math and science STVs resulted in students following the same STEM pathways. These findings corroborate our previous conclusion that a within-person relatively high math and science STVs with an upward trend appears to be the optimal pattern of motivational beliefs to move students toward STEM pathways. 


\section{Gendered Trajectories and STEM Outcomes}

Gender differences in STVs were identified for all subject domains at grade 9: Males placed more value on math and science, whereas females had higher STVs for Finnish and social subjects. This finding suggests that gender differences in STVs appear to emerge in early school years. While Jacobs et al. (2002; also see Watt, 2004) reported that gender differences in math STVs remain stable during high school transition, we observed a clear gender divergence in math and science STVs, that stemmed from a greater decline in females' STVs. The gender gap in math and science motivation is associated with an intensification of gendered socialization pressures by parents, peers, media, and schools (Eccles, 2009). In particular, such intensification is more salient for females' science learning at the onset of puberty, given that science is perceived as a more stereotypically masculine domain than math (Fredricks \& Eccles, 2002). Hence, a larger gender gap was identified since math and science STVs were operationalized as a single construct in this study.

Gender differences in both between- and within-person mechanisms in relation to different STVs significantly explained gender disparities in STEM aspirations and participation. In particular, our results suggest that gender differences in how individuals prioritize and develop STVs across domains may play a more prominent role in directing STEM educational and occupational pathways as compared to those in absolute levels of STVs. Females were more likely to place relatively low STVs on math and science, experience a downward trend in math and science, and experience an upward trend in Finnish STVs than males. Males were more likely to experience reverse motivational trajectories, even though some may have even lower STVs in math and science compared to females at grade 9. These gendered motivational trajectories provide the foundation for gendered educational and career development. 


\section{Generalizability of the Results to Other Educational Contexts}

As the Finnish high school transition is characterized by the separation of academic and vocational tracks, and implementation of course-by-course tracking, it is a useful context for examining within-person development trends in motivation. Low but Increasing Math and Science as well as the High and Increasing Finnish trajectories indicate that differentiated curriculum and course schedules offered by Finnish high schools nurture personal interests in specific domains. These findings may be generalizable to other education contexts that have similar school curricula, indicating that high school transition in these settings may also serve as a turning point for enhancing or undermining STVs in adolescents. However, in countries like the U.S, where course-by-course tracking in some subjects (e.g., math) typically begins earlier (e.g., in grade 7 or 8), the middle school transition maybe a more important turning point for students' interests and career aspirations.

A long post-high school transition period is another key feature of the Finnish educational system. Although we were able to link motivational trajectories to an individual's STEM participation six years after post-high school transition, many participants were still studying in university at that time point, which did not allow us to assess their ultimate career fields. However, the delayed exposure to higher education, makes a strong case for testing the effect of motivational trajectory on educational and career choices. During the post-high school transition, students may have difficulty keeping up their STEM career aspirations because most STEM majors require higher marks in matriculation exams and students often need to apply multiple times for university STEM programs. Both of these encounters may lead individuals to re-initiate their career exploration processes. The strong predictive effect of motivational trajectory profiles suggests that relative STVs in high school highly influence long-term career- 
related behavior choices. While providing a satisfactory setting for this study, the special features of the Finnish educational system warrant future research to investigate whether our findings can be replicated in differing systems.

\section{Limitations and Further Research}

This study has several limitations, and some caveats must be noted. First, students' EVT motivation scale used in this study limited the significance of our finding. Specifically, we did not include academic ability self-concept (i.e., expectancy of success), a variable that has been shown to significantly predict STEM participations (Wang \& Degol, 2013). It should be noted that previous studies (Archambault et al., 2010; Wang et al., 2017) examined the joint trajectories of self-concept and STVs in a single domain across time and found that self-concept was accompanied with highly similar changes in STVs. Indeed, self-concept and STV beliefs are reciprocally related and mutually reinforcing over time: students are more interested in domains in which they feel more competent, and they achieve greater competence in domains where they have greater interest (Eccles, 2009; Pinxten, Marsh, De Fraine, Van Den Noortgate, \& Van Damme, 2014). We also did not consider the negative aspect of task value: cost, which has been shown to predict academic performance, effort exertion, and engagement above and beyond other aspects of task value (e.g., Guo et al., 2016). Dimensional comparison processes have also been found to play a salient role in constructing domain-specific perceived cost (Gaspard et al., 2018) and the impact of such comparison processes on the development of task value would be stronger in high school, which subsequently influence career choices (Eccles, 2009). Importantly, recent work by Hulleman and his colleagues (e.g., Barron \& Hulleman, 2015; Kosovich, Hulleman, Barron, \& Getty, 2015; Hulleman, Barron, Kosovich, Lazowski, 2016) illustrated that inclusion of cost items in the task value scale undermined its factor structure (it is 
also evident in our current sample) and concluded that cost should be treated as a separate factor in EVT research. Thus, in this study the task value scale was measure by intrinsic, attainment, and utility value components. However, adding a new construct (i.e., cost, self-concept) in three subject domains would introduce a large number of additional estimated parameters and greatly increase the complexity of GMM analysis. As such, the GMM models may converge on statistically improper solutions, or it may not to converge at all (Meyer \& Morin, 2016). Additionally, only a single item was used to capture each value facet (intrinsic, attainment, utility value) and to form a task value scale. Recent work has showed that it is important to include different value facets under each value component (e.g., daily life, school, and job utility, Gaspard et al., 2018), particularly when looking at their predictions of achievement-related behaviors (Guo et al., 2016). As mentioned earlier, math and science STVs were operationalized as a single construct, which substantially limited our ability to detect the motivational mechanism channeling people to different STEM sub-disciplines. For example, incorporating math physics, chemistry, and biology would allow us to evaluate the nuanced predictive contribution of joint motivational trajectories to entering mathematics, physics, engineering, and computer sciences versus health, biological, and medical sciences fields (Eccles \& Wang, 2016). Thus, the further inclusion of multiple domain-specific science self-concept and four facets of task values based on multiple-item measurement scales would provide a more comprehensive understanding of the developmental trajectories of motivational beliefs and how they shape career pathways.

Second, the current findings are correlational, therefore no causal inferences can be made. There is a need for carefully constructed longitudinal panel studies and experimental interventions to better understand the causal mechanisms between joint developmental 
trajectories in STVs and career decision-making process. Third, previous studies have indicated that the changes in students' STV s over time tended to follow a curvilinear trajectory rather than a linear pattern (Musu-Gillette et al., 2015; Wang et al., 2017). However, we were unable to test if the joint changes across domains occur in a curvilinear fashion given the inclusion of only three waves of data for the academic motivation variable. Future research should examine these questions via a life-span longitudinal design.

Fourth, the task value repeated measures in this study were non-normally distributed (negative skew), which may produce artificial groups in GMM (Bauer, 2007). Because GMM assumes that repeated measures are normally distributed within classes in fact, a variety of nonnormal shapes can be derived from a mixture of normal distributions, even in the absence of true population subgroups (Bauer \& Curran, 2003). Although cross-validation analysis revealed that the three-class solution performed well in this study, there is clearly a need to replicate the results using same kind of Finland samples. Future studies can also consider incorporating qualitative interviews to better understand Finnish adolescents' motivational changes across different subject domains and the potential mechanisms that may drive those changes.

Furthermore, participants were drawn from a single Finlandian state, which did not allow us to examine and compare the roles of socio-cultural and national differences in family and school environment. For example, nations differ in the perception of gendered stereotypes linked to STEM and non-STEM occupations (Eccles \& Wang, 2016). Thus, the cross-cultural variations in socialization and gender-role processes that influence choices of educational and occupational pathways indicate that comparative studies in more diverse settings are needed to advance our understanding of career choices. 
Another limitation is that this study assessed individual student data only and did not include, for example, school records of students' GPA. Previous empirical findings have suggested that there are high correlations between students' self-reported achievements and their actual grade point averages (Holopainen \& Savolainen, 2005). However, self-reported grades should be used with caution as they might contain some error due to inflated estimates or mistaken recall, particularly for low-achieving students (Kuncel, Credé, \& Thomas, 2005).Hence, future research should seek participants' permission to obtain grades from school records instead of relying on students' self-reported scores.

Lastly, as course selection lead students to different local class contexts that in turn may have shaped their relative strengths of motivation across subject domains, it would be beneficial to investigate the association between high school STEM participations and developmental trajectories of STV in future research.

\section{Implications for Practice and Research}

Despite these limitations, the current study has implications for intervention and practice. First, while the average trends in STVs across domains were relatively stable from grades 9 to 11, the substantial heterogeneity in the joint STV trajectories was evident. The distinct developmental patterns characterized by divergent individual academic experiences enable us to develop more specifically targeted and nuanced strategies to direct students toward STEM educational and occupational pathways. For example, our findings suggest continued increases in math and science STVs may propel students toward STEM pathways. Interventions designed to increase students' perceptions of the relevance of math and science to their lives through teachers and parents have been effective in triggering students' interest and promoting academic performance in STEM topics (Lazowski \& Hulleman, 2016). 
Second, our findings support dimensional comparison theory (Möller \& Marsh, 2013) and suggest that boosting STVs in the verbal domain would lead to a corresponding drop in math and science STVs (and vice versa). Such contrasting comparison processes are associated with gendered educational and occupational pathways. Indeed, a recent intervention study targeting math motivation demonstrated that one intervention successfully promoted students' math STVs but simultaneously produced negative side effects on STVs in verbal domains (Gaspard et al., 2016). One way to resolve this dilemma might be to build connections between school subjects in curriculum development. Cross-curriculum connections would help to foster and reinforce students' general motivation in learning across all academic subjects, rather than only in the few subjects in which they fell they perform best (see Gaspard et al., 2016). Alternatively, teachers and parents should be aware of dimensional comparison processes and help students adjust the perceptions of subject (dis)similarity, as the contrast effects seem to depend on students' beliefs about the association between mathematical and verbal abilities. For example, it could be beneficial to show students quite explicitly the similarities between different school subjectsattribution of achievement in every subject to interest, effort, and learning strategies (Helm, Mueller-Kalthoff, Nagy, \& Möller, 2016).

Finally, our findings suggest that the relative hierarchy of STVs across domains at grade 9 is substantially associated with subsequent motivational development, that constrains one's options in educational and occupational pursuits. Our results underscore the importance of optimizing early math and science learning experiences to facilitate and maintain high levels of STVs in both domains. Secondary school has been noted as a time when students tend to experience cognitive difficulties in learning and develop negative motivational beliefs about learning. These facts make the school transition an optimal time for interventions that target 
students' achievement motivation. Research on educational interventions suggests that welltimed, carefully crafted interventions have the potential to change students' long-term academic trajectories by nudging them into more advanced institutional channels (Goyer et al., 2017). For example, early preventive interventions focusing on positive school experiences, such as increasing exposure to female scientists and challenging stereotypes of science masculinity (Wang \& Degol, 2016), may be beneficial in promoting females' motivation and engagement in STEM activities. However, we call for research that uses a longitudinal design that focuses on the long-term outcomes assicated with such interventions, given that the evidence on the effectiveness of existing STEM motivation interventions is still preliminary (Rosenzweig \& Wigfield, 2016).

\section{Conclusion}

Our study makes new contributions to the field by incorporating variable- and patterncentered approaches in the study of motivational trajectories, their associations with educational and occupational STEM pathways, and the critical stage of adolescence when nascent future plans begin to firmly materialize. First, results showed that students developed specific interests in particular domains during high school transition even though averaged developmental changes across domains remained relatively stable. Therefore, studies that focus on average trends in student motivation may be masking variability in these developmental processes. Furthermore, this study is the first to incorporate multiple academic domains and demonstrate how intrapersonal dimensional comparison processes influence different groups of students that develop divergent motivation across domains. These domain-specific motivational trajectories interact with each other to shape a relative hierarchy of STVs. The relative (not absolute) STVs play a critical role in explaining individual and gender difference in STEM pathways; yet, the 
extant empirical research on gender imbalance at earlier stages in STEM trajectories focuses almost exclusively on females' motivation changes in a single domain (math or science), with correspondingly little attention to how changes of STVs across domains differentially impact females' choices. Our study, therefore, calls attention to the importance of examining population subgroups in motivation changes and highlights the need for more research that focuses on individual and gender differences in the development of the relative motivation hierarchy across academic domains during the formative stages of adolescence. Distinct developmental patterns and divergent outcomes provide important information for those designing effective trajectoryspecific intervention strategies that target students' motivation over time. 


\section{References}

Archambault, I., Eccles, J. S., \& Vida, M. N. (2010). Ability self-concepts and subjective value in literacy: Joint trajectories from grades 1 through 12. Journal of Educational Psychology, 102(4), 804-816. doi: 10.1016/j.jclinepi.2007.11.014

Barron, K. E., \& Hulleman, C. S. (2015). The expectancy-value- cost model of motivation. In J. D. Wright (Ed.), International encyclopedia of the social and behavioral sciences (2nd ed.). Oxford, UK: Elsevier.

Bauer, D. J. (2007). Observations on the use of growth mixture models in psychological research. Multivariate Behavioral Research, 42(4), 757786. doi:10.1080/00273170701710338

Bauer, D. J., \& Curran, P. J. (2003). Distributional assumptions of growth mixture models: Implications for overextraction of latent trajectory classes. Psychological Methods, 8(3), 338-363. doi:10.1037/1082-989X.8.3.338

Chow, A., Eccles, J. S., \& Salmela-Aro, K. (2012). Task value profiles across subjects and aspirations to physical and IT-related sciences in the United States and Finland. Developmental Psychology, 48(6), 1612-28. doi: 10.1037/a0030194

Davis-Kean, P. E., \& Jager, J. (2014). Trajectories of achievement within race/ethnicity: "Catching up" in achievement across time. Journal of Educational Research, 107(3), 197-208. doi: 10.1080/ 00220671.2013.807493

Diallo, T. M. O., Morin, A. J. S., \& Lu, H. (2016). Impact of misspecifications of the latent variance-covariance and residual matrices on the class enumeration accuracy of growth mixture models. Structural Equation Modeling, 5511, 1-25. doi: $10.1080 / 10705511.2016 .1169188$ 
Dotterer, A. M., McHale, S. M., \& Crouter, A. C. (2009). The development and correlates of academic interests from childhood through adolescence. Journal of Educational Psychology, 101(2), 509-519. doi: 10.1037/a0013987

Eccles, J. S. (2009). Who am I and what am I going to do with my life? Personal and collective identities as motivators of action. Educational Psychologist, 44, 78-89. doi:10.1080/00461520902832368

Eccles, J. S., Adler, T. F., Futterman, R., Goff, S. B., Kaczala, C. M., Meece, L. J., \& Midgley, C. (1983). Expectancies, values, and academic behaviors. In J. T. Spence (Ed.), Achievement and achievement motivation: Psychological and sociological approaches (pp. 75-146). San Francisco, CA: Freeman.

Eccles, J. S., Midgley, C., Wigfield, A., Buchanan, C. M., Reuman, D., Flanagan, C., \& Iver, D. Mac. (1993). Development during adolescence. American Psychologist, 48(2), 90-101. doi:10.1037/0003-066X.48.2.90

Eccles, J. S., \& Wang, M.-T. (2016). What motivates females and males to pursue careers in mathematics and science? International Journal of Behavioral Development, 40(2), 100106. https://doi.org/10.1177/0165025415616201

Enders, C. (2010). Applied missing data analysis. New York, NY: Guilford Press.

Fredricks, J. A., \& Eccles, J. S. (2002). Children's competence and value beliefs from childhood through adolescence: growth trajectories in two male-sex-typed domains. Developmental Psychology, 38(4), 519-533. Doi:10.1037//0012-1649.38.4.519

Gaspard, H., Dicke, A.-L., Flunger, B., Häfner, I., Brisson, B. M., Trautwein, U., \& Nagengast, B. (2016). Side effects of motivational interventions? Effects of an Intervention in math 
classrooms on motivation in verbal domains. AERA Open, 2(2), 1-14.

doi: $10.1177 / 2332858416649168$

Gaspard, H., Wigfield, A., Jiang, Y., Nagengast, B., Trautwein, U., \& Marsh, H. W. (2018).

Dimensional comparisons: How academic track students' achievements are related to their expectancy and value beliefs across multiple domains. Contemporary Educational Psychology, 52, 1-14. doi:10.1016/j.cedpsych.2017.10.003

Gottfried, A. E., Marcoulides, G. a., Gottfried, A. W., Oliver, P. H., \& Guerin, D. W. (2007). Multivariate latent change modeling of developmental decline in academic intrinsic math motivation and achievement: Childhood through adolescence. International Journal of Behavioral Development, 31(4), 317-327. doi:10.1177/0165025407077752

Gottfried, A. E., Marcoulides, G. A., Gottfried, A. W., \& Oliver, P. H. (2013). Longitudinal pathways from math intrinsic motivation and achievement to math course accomplishments and educational attainment. Journal of Research on Educational Effectiveness, 6(1), 68-92. doi:10.1080/19345747.2012.698376

Goyer, J. P., Garcia, J., Purdie-Vaughns, V., Binning, K. R., Cook, J. E., Reeves, S. L., ... Cohen, G. L. (2017). Self-affirmation facilitates minority middle schoolers’ progress along college trajectories. Proceedings of the National Academy of Sciences, 114(29), 7594-7599. doi:10.1073/pnas.1617923114

Guo, J., Eccles, J. S., Sortheix, F. M., \& Salmela-Aro, K. (2018). Gendered Pathways Toward STEM Careers: The Incremental Roles of Work Value Profiles Above Academic Task Values. Frontiers in Psychology, 9, 1-15. doi: 10.3389/fpsyg.2018.01111

Guo, J., Marsh, H. W., Parker, P. D., Morin, A. J. S., \& Dicke, T. (2017). Extending expectancyvalue theory predictions of achievement and aspirations in science: Dimensional 
comparison processes and expectancy-by-value interactions. Learning and Instruction, 49, 81-91. doi:10.1016/j.learninstruc.2016.12.007

Guo, J., Marsh, H. W., Parker, P. D., Morin, A. J. S., \& Yeung, A. S. (2015). Expectancy-value in mathematics, gender and socioeconomic background as predictors of achievement and aspirations: A multi-cohort study. Learning and Individual Differences, 37, 161-168. doi: 10.1016/j.lindif.2015.01.008

Guo, J., Nagengast, B., Marsh, H. W., Kelava, A., Gaspard, H., Brandt, H., ... Trautwein, U. (2016). Probing the Unique Contributions of Self-Concept, Task Values, and Their Interactions Using Multiple Value Facets and Multiple Academic Outcomes. AERA Open, 2(1), 1-20. doi: 10.1177/2332858415626884

Guo, J., Parker, P. D., Marsh, H. W., \& Morin, A. J. S. (2015). Achievement, motivation, and educational choices: A longitudinal study of expectancy and value using a multiplicative perspective. Developmental Psychology, 51(8), 1163-1176. doi:10.1037/a0039440

Grimm, K. J., Ram, N., \& Estabrook, R. (2017). Growth modeling: structural equation and multilevel modeling approaches. New York: Guilford Press.

Grimm, K. J., Mazza, G. L., \& Davoudzadeh, P. (2017). Model selection in finite mixture models: A k -fold cross-validation approach. Structural Equation Modeling: A Multidisciplinary Journal, 24(2), 246-256. doi:10.1080/10705511.2016.1250638

Helm, F., Mueller-Kalthoff, H., Nagy, N., \& Moller, J. (2016). Dimensional comparison theory: perceived subject similarity impacts on students self-concepts. AERA Open, 2(2), 1-9. doi:10.1177/2332858416650624 
Jacobs, J. E., Lanza, S., Osgood, D. W., Eccles, J. S., \& Wigfield, A. (2002). Changes in children's self-competence and values: Gender and domain differences across grades one through twelve. Child Development, 73(2), 509-527. doi:10.1111/1467-8624.00421

Kosovich, J. J., Hulleman, C. S., Barron, K. E., \& Getty, S. (2015). A Practical Measure of Student Motivation. The Journal of Early Adolescence, 35(5-6), 790-816. doi: $10.1177 / 0272431614556890$

Kuncel, N. R., Credé, M., \& Thomas, L. L. (2005). The validity of self-reported grade point averages, class ranks, and test scores: A meta-analysis and review of the literature. Review of Educational Research, 75(1), 63-82. doi:10.3102/00346543075001063

Holopainen, L., \& Savolainen, H. (2005). The validity of self-reported grade point average (Unpublished raw data), Finland: University of Joensuu and University of Jyväskylä.

Huang, B., Sivaganesan, S., Succop, P., \& Goodman, E. (2004). Statistical assessment of mediational effects for logistic mediational models. Statistics in Medicine, 23(17), 27132728. doi:10.1002/sim. 1847

Hulleman, C. S., Barron, K. E., Kosovich, J. J., \& Lazowski, R. A. (2016). Current theories, constructs, and interventions within an expectancy value framework. In A. A. Lipnevich, F. Preckel, \& R. D. Roberts (Eds.), Psychosocial skills and school systems in the twentyfirst century: Theory, research, and applications, 1st edition (pp. 241-278). Springer International Publishing.

Lazowski, R. A., \& Hulleman, C. S. (2016). Motivation interventions in education: A metaanalytic review. Review of Educational Research, 86(2), 602-640. doi: $10.3102 / 0034654315617832$ 
Lauermann, F., Tsai, Y.-M., \& Eccles, J. S. (2017). Math-related career aspirations and choices within Eccles et al.'s expectancy-value theory of achievement-related behaviors. Developmental Psychology, 53(8), 1540-1559. doi:10.1037/dev0000367

Lo, Y., Mendell, N., \& Rubin, D. B. (2001). Testing the number of components in a normal mixture. Biometrika, 88, 767-778. doi: 10.1093/biomet/88.3.767

Lubke, G., \& Muthén, B. O. (2007). Performance of factor mixture models as a function of model size, criterion measure effects, and class-specific parameters. Structural Equation Modeling, 14, 26-47.doi: 10.1080/10705510709336735

Marsh, H. W. (2007). Self-concept theory, measurement and research into practice: The role ofself-concept in educational psychology. Leicester, UK: British Psychological Society.

Marsh, H. W., Byrne, B. M., \& Shavelson, R. J. (1988). A multifaceted academic self-concept: Its hierarchical structure and it relation to academic achievement. Journal of Educational Psychology, 80, 366-380.

Marsh, H. W., Lüdtke, O., Nagengast, B., Trautwein, U., Abduljabbar, A. S., Abdelfattah, F., \& Jansen, M. (2015). Dimensional comparison theory: Paradoxical relations between selfbeliefs and achievements in multiple domains. Learning and Instruction, 35, 16-32. doi: 10.1016/j.learninstruc.2014.08.005

Miller, D. I., Eagly, A. H., \& Linn, M. C. (2015). Women's representation in science predicts national gender-science stereotypes: Evidence from 66 nations. Journal of Educational Psychology, 107, 631-644. doi:10.1037/edu0000005

Miller, J. D., \& Kimmel, L. G. (2012). Pathways to a STEMM profession. Peabody Journal of Education, 87, 26-45. doi:10.1080/0161956X.2012.642274 
Mok, M. M. C., McInerney, D. M., Zhu, J., \& Or, A. (2014). Growth trajectories of mathematics achievement: Longitudinal tracking of student academic progress. The British Journal of Educational Psychology. 85(2), 154-171. doi:10.1111/bjep.12060

Meyer, J. P., \& Morin, A. J. S. (2016). A person-centered approach to commitment research: Theory, research, and methodology. Journal of Organizational Behavior, 37(4), 584 612. doi:10.1002/job.2085

Morin, A. J. S., \& Marsh, H. W. (2015). Disentangling shape from level effects in personcentered analyses: an illustration based on university teachers' multidimensional profiles of effectiveness. Structural Equation Modeling, 22(1), 39-59. doi:10.1080/10705511.2014.919825

Möller, J., \& Marsh, H. W. (2013). Dimensional comparison theory. Psychological Review, 120, 544-560. doi:10.1037/a0032459

Möller, J., Helm, F., Müller-Kalthoff, H., Nagy, N., \&Marsh, H.W. (2015). Dimensional comparisons and their consequences for self-concept, motivation, and emotion. International Encyclopedia of the Social \& Behavioral Sciences, 26, 430-436. doi:10.1016/B978-0-08-097086-8.26092-3

Musu-Gillette, L. E., Wigfield, A., Harring, J. R., \& Eccles, J. S. (2015). Trajectories of change in students' self-concepts of ability and values in math and college major choice. Educational Research and Evaluation, 21(4), 343-370. doi:10.1080/13803611.2015.1057161

Muthén, B. O. (2001). Latent variable mixture modeling. In G. Marcoulides \& R. Schumacker (Eds.), New developments and techniques in structural equation modeling (pp. 1-33). Mahwah, NJ: Erlbaum. 
Muthén, B. (2003). Statistical and substantive checking in growth mixture modeling: comment on Bauer and Curran (2003). Psychological Methods, 8(3), 369-377. doi:10.1037/1082$\underline{989 X .8 .3 .369}$

Petersen, J. L., \& Hyde, J. S. (2017). Trajectories of self-perceived math ability, utility value and interest across middle school as predictors of high school math performance. Educational Psychology, 37(4), 438-456. doi:10.1080/01443410.2015.1076765

Pinxten, M., Marsh, H. W., De Fraine, B., Van Den Noortgate, W., \& Van Damme, J. (2014). Enjoying mathematics or feeling competent in mathematics? Reciprocal effects on mathematics achievement and perceived math effort expenditure. British Journal of Educational Psychology, 84(1), 152-174. doi:10.1111/bjep.12028

Rosenzweig, E. Q., \& Wigfield, A. (2016). STEM motivation interventions for adolescents: A promising start, but further to go. Educational Psychologist, 51(2), 146-163. doi:10.1080/00461520.2016.1154792

Rubin, D. B. (1987). Multiple imputation for nonresponse in surveys. New York: John Wiley \& Sons.

Sahdra, B. K., Ciarrochi, J., Parker, P. D., Basarkod, G., Bradshaw, E. L., \& Baer, R. (2017). Are people mindful in different ways? Disentangling the quantity and quality of mindfulness in latent profiles and exploring their links to mental health and life effectiveness. European Journal of Personality, 31(4), 347-365. doi:10.1002/per.2108

Salmela-Aro, K., \& Tynkkynen, L. (2012). Gendered pathways in school burnout among adolescents. Journal of Adolescents, 35, 929-939. doi:10.1016/j.adolescence.2012.01.001

Schurtz, I. M., Pfost, M., Nagengast, B., \& Artelt, C. (2014). Impact of social and dimensional comparisons on student's mathematical and English subject interest at the beginning of 
secondary school. Learning and Instruction, 34, 32-41.

doi:10.1016/j.learninstruc.2014.08.001

Sortheix, F. M., Chow, A., \& Salmela-Aro, K. (2015). Work values and the transition to work life: A longitudinal study. Journal of Vocational Behavior, 89, 162-171.

Statistics of Finland (1989). Sosioekonominen luokitus [Classification ofsocio-economic groups]. Statistics Finland: Helsinki.

Stegmann, G., \& Grimm, K. J. (2018). A new perspective on the effects of covariates in mixture models. Structural Equation Modeling, 25(2), 167-178. doi:10.1080/10705511.2017.1318070

Stoet, G., \& Geary, D. C. (2018). The gender-equality paradox in science, technology, engineering, and mathematics education. Psychological Science, 29(4), 581-593. doi:10.1177/0956797617741719

Tan, J. B., \& Yates, S. (2011). Academic expectations as sources of stress in Asian students. Social Psychology of Education, 14, 389-407. doi:10.1007/s11218-010-9146-7

Wang, M.-T., Chow, A., Degol, J. L., \& Eccles, J. S. (2017). Does everyone's motivational beliefs about physical science decline in secondary school?: Heterogeneity of adolescents' achievement motivation trajectories in physics and chemistry. Journal of Youth and Adolescence, 46(8), 1821-1838. doi:10.1007/s10964-016-0620-1

Wang, M.-T., \& Degol, J. L., (2013). Motivational pathways to STEM career choices: Using expectancy-value perspective to understand individual and gender differences in STEM fields. Developmental Review, 33(4), 304-340. doi:10.1016/j.dr.2013.08.001

Wang, M.-T., \& Degol, J. L. (2016). Gender gap in science, technology, engineering, and mathematics (STEM): Current knowledge, implications for practice, policy, and future 
directions. Educational Psychology Review, 29(1), 119-140. doi:10.1007/s10648-0159355-x

Wang, M., Degol, J., \& Ye, F. (2015). Math achievement is important, but task values are critical, too: Examining the intellectual and motivational factors leading to gender disparities in STEM careers. Frontiers in Psychology, 6(36).

doi:10.3389/fpsyg.2015.00036

Watt, H. M. G. (2004). Development of adolescents' self-perceptions, values, and task perceptions according to gender and domain in 7th- through 11th-grade Australian students. Child Development, 75(5), 1556-74. doi:10.1111/j.1467-8624.2004.00757.x

Wigfield, A., Tonks, S., \& Klauda, S. L. (2016). Expectancy-value theory. In K. R.Wentzel, \& D. B. Miele (Eds.), Handbook of Motivation at School (pp. 55-74). New York: Routledge. 
Table 1

Research Questions, Hypothesis, and Approaches

Research questions Specific hypothesis

Approach

Q1 H1a: The average, joint trajectories of

- On average, initial levels of students' STVs across domains (at ninth grade)
would be moderate given that STVs are likely to follow a general decline during

the three domai

Variable-

specific STVs over elementary and junior high school; average STV trends in the three subject domains

time. would be relatively stable (unchanged or slightly declining) during high school

H1b: Prediction of transition

STEM aspirations and

- $\quad$ Math and science STVs at ninth grade would predict a higher likelihood of

participation. aspirations and entry into STEM fields, whereas STVs in language and social subjects would predict lower STEM aspirations and engagement

\section{H1c: Gendered}

trajectories.

- $\quad$ Males would place higher value on math and science than females, whereas females would hold higher values for Finnish and social subjects than males. The gender gap in STVs across different domains will remain stable or decline and are expected to explain gender imbalance in STEM aspirations and participation.

Q2 H2a: The joint trajectories of the three domain-specific STVs over time.

- The existence of at least three groups or classes in concordance with prior theoretical work: (1) a rise in Finnish STVs would couple with a decline in math and science STVs; (2) a trajectory where students report elevated math and science STVs over time, coupled with a decline in Finnish STVs; (3) a declining trajectory where students report a slight and constant decline in STVs across the three subjects. We left it as an open research question as to how social subjects STVs interact with Finnish and math/science over time to shape the joint trajectories given the absence of empirical evidence.

\begin{tabular}{ll}
\hline H2b: Prediction of & $\bullet \quad$ Students with a developmental trajectory characterized by increasing math \\
STEM aspirations and & and science would be more likely to move towards STEM over non-STEM fields, as
\end{tabular}

STEM aspirations an and science would be more likely to move towards STEM over non-STEM fields, as participation compared to those in other trajectory groups.

H2c: Gendered $\quad \bullet \quad$ Males would be over-represented in the increasing math and science

trajectories. trajectory, whereas females would be over-represented in the increasing Finnish (or social subjects) trajectory.

- $\quad$ These gender differences in trajectory distribution should partially explain gender differences in STEM outcomes. 
Table 2

Descriptive Statistics and Intercorrelations Among Key Variables

\begin{tabular}{|c|c|c|c|c|c|c|c|c|c|c|c|c|c|c|c|}
\hline Variables & 1 & 2 & 3 & 4 & 5 & 6 & 7 & 8 & 9 & 10 & 11 & 12 & 13 & 14 & 15 \\
\hline 1. Grade 9: Finnish STV & - & & & & & & & & & & & & & & \\
\hline 2. Grade 10: Finnish STV & $.66^{*}$ & - & & & & & & & & & & & & & \\
\hline 3. Grade 11: Finnish STV & $.52 *$ & $.82 *$ & - & & & & & & & & & & & & \\
\hline 4. Grade 9: Math/Science STV & $.38 *$ & $.22 *$ & $.26^{*}$ & - & & & & & & & & & & & \\
\hline 5. Grade 10: Math/Science STV & $.18^{*}$ & $.29 *$ & $.23 *$ & $.62 *$ & - & & & & & & & & & & \\
\hline 6. Grade 11: Math/Science STV & .05 & .04 & $.18^{*}$ & $.58^{*}$ & $.72 *$ & - & & & & & & & & & \\
\hline 7. Grade 9: Social studies STV & $.57 *$ & $.41 *$ & $.39 *$ & $.47^{*}$ & $.29 *$ & $.18^{*}$ & - & & & & & & & & \\
\hline 8. Grade 10: Social studies STV & $.39 *$ & $.53 *$ & $.58 *$ & $.26^{*}$ & $.20 *$ & .15 & $.59 *$ & - & & & & & & & \\
\hline 9. Grade 11: Social studies STV & $.34 *$ & $.47 *$ & $.54 *$ & .11 & .09 & .10 & $.51 *$ & $.69 *$ & - & & & & & & \\
\hline 10. Gender & $-.29 *$ & $-.31 *$ & $-.26^{*}$ & $.15^{*}$ & $.18 *$ & $.21 *$ & $-.15^{*}$ & $-.20 *$ & $-.16^{*}$ & - & & & & & \\
\hline 11. Finnish Matriculation & .12 & $.18^{*}$ & $.27 *$ & -.10 & -.12 & $-.16^{*}$ & .08 & .12 & $.16^{*}$ & -.08 & - & & & & \\
\hline 12. Math Matriculation & -.08 & $-.15^{*}$ & $-.18 *$ & .12 & $.16^{*}$ & $.23 *$ & -.02 & -.08 & -.13 & -.01 & $.23 *$ & - & & & \\
\hline 13. SES & .01 & .05 & .06 & .09 & .01 & -.01 & .03 & .10 & .09 & .00 & .13 & .12 & - & & \\
\hline 14. STEM aspirations & $-.20 *$ & $-.22 *$ & $-.22 *$ & $.16^{*}$ & $.24 *$ & $.31 *$ & $-.18 *$ & $-.16^{*}$ & $-.22 *$ & $.34 *$ & .02 & $.18^{*}$ & $-23 *$ & - & \\
\hline 15. STEM participation & $-.24 *$ & $-.23 *$ & $-.29 *$ & $.13 *$ & $.22 *$ & $.27 *$ & $-.17 *$ & $-.18^{*}$ & $-.21 *$ & $.39 *$ & .02 & $.17 *$ & $-.22 *$ & $.66^{*}$ & - \\
\hline$M$ & 4.91 & 4.93 & 4.93 & 4.84 & 4.82 & 4.71 & 4.83 & 4.78 & 4.79 & .52 & 5.41 & 5.23 & 3.22 & 2.30 & 2.26 \\
\hline$S D$ & 1.09 & 1.17 & 1.04 & 1.10 & 1.14 & 1.09 & 1.07 & 1.14 & 1.12 & .50 & 2.07 & 2.09 & .68 & .46 & .44 \\
\hline Skewness & -.89 & -.77 & -.64 & -.78 & -.66 & -.59 & -.74 & -.55 & -.66 & - & .22 & .23 & -.31 & - & - \\
\hline Kurtosis & .70 & .20 & .08 & 0.50 & .13 & .25 & .77 & .06 & .57 & - & -.97 & -.97 & -.86 & - & - \\
\hline Range & $\begin{array}{l}1.07- \\
6.65\end{array}$ & $\begin{array}{l}1.09- \\
6.68 \\
\end{array}$ & $\begin{array}{l}1.19- \\
6.59\end{array}$ & $\begin{array}{l}1.15- \\
6.44\end{array}$ & $\begin{array}{l}1.06- \\
6.50 \\
\end{array}$ & $\begin{array}{l}1.09- \\
6.55\end{array}$ & $\begin{array}{l}1.21- \\
6.80 \\
\end{array}$ & $\begin{array}{l}.99- \\
6.70 \\
\end{array}$ & $\begin{array}{l}1.20- \\
6.73 \\
\end{array}$ & - & $0-6$ & $0-6$ & $1-4$ & - & - \\
\hline
\end{tabular}


Table 3

Estimated Initial Levels and Rates of Change Based on Latent Curve Model

\begin{tabular}{|c|c|c|c|c|c|c|c|c|c|}
\hline \multirow[b]{2}{*}{ Task value } & \multicolumn{2}{|c|}{$\begin{array}{l}\text { Unconditional } \\
\text { Multivariate LCM }\end{array}$} & \multicolumn{7}{|c|}{ Conditional Multivariate LCM } \\
\hline & Intercept & Slope & Intercept & Slope & $\begin{array}{l}\text { Covariate } \\
\text { (Gender) } \\
\text { effect on } \\
\text { intercept }\end{array}$ & $\begin{array}{l}\text { Covariate } \\
\text { (SES) } \\
\text { effect on } \\
\text { intercept }\end{array}$ & $\begin{array}{l}\text { Covariate } \\
\text { (Gender) } \\
\text { effect on } \\
\text { slope }\end{array}$ & $\begin{array}{l}\text { Covariate } \\
\text { (SES) } \\
\text { effect on } \\
\text { slope }\end{array}$ & $\begin{array}{l}\text { Time-varying Covariate } \\
\text { (GPA) effects on task value } \\
\text { (range) }\end{array}$ \\
\hline Finnish & $4.92 * * *$ & -.00 & $5.11 * * *$ & -.04 & $-.55 * * *$ & -.04 & -.05 & $.06^{*}$ & from .21 to $.23 * * *$ \\
\hline Math and science & $4.86^{* * *}$ & $-.07 *$ & $4.73 * * *$ & $-.11 *$ & $.26^{* *}$ & .01 & $.10^{*}$ & -.04 & from .17 to $25^{* * *}$ \\
\hline Social subjects & $4.82 * * *$ & -.03 & $4.99 * * *$ & -.02 & $-.32 * * *$ & -.02 & 0.03 & .06 & from .17 to $.29 * * *$ \\
\hline
\end{tabular}

Note. $* * *<.001 ; * *<.01, *<.05$.

Table 4

Correlations and Variances between Estimated Levels and Rates of Change of Task Value across Subject Domains Based on the Unconditional LCM

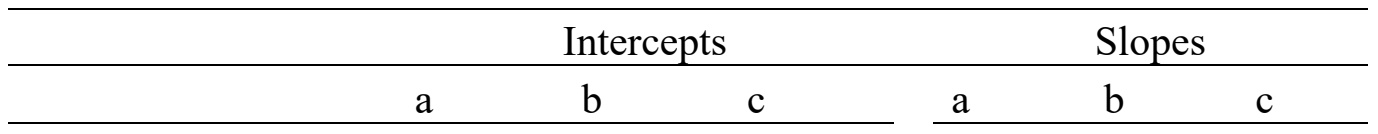

Intercepts

(a) Finnish

(b) Math and science $.50 * * * \quad-$

(c) Social subjects $\quad .63 * * * \quad .47 * * * \quad-$

Slopes

\begin{tabular}{lllllll} 
(a) Finnish & $-.18^{* *}$ & $-.17 * * *$ & $-.15 * *$ & - & & \\
(b) Math and science & $-.20^{* * *}$ & -.08 & $-.20^{* * *}$ & $.13^{*}$ & - & \\
(c) Social subjects & $-.19 * * *$ & $-.19 * * *$ & -.12 & $.20^{* * *}$ & $.18^{* * *}$ & - \\
\hline Variances & $.68 * * *$ & $.61 * * *$ & $.68 * * *$ & $.32 * * *$ & $.34 * *$ & $.28 * *$
\end{tabular}

Note. $* * *<.001 ; * *<.01, *<.05$. 
Table 5

The Levels and Rates of Change Predicting STEM Outcomes Based on the Unconditional LCM Model

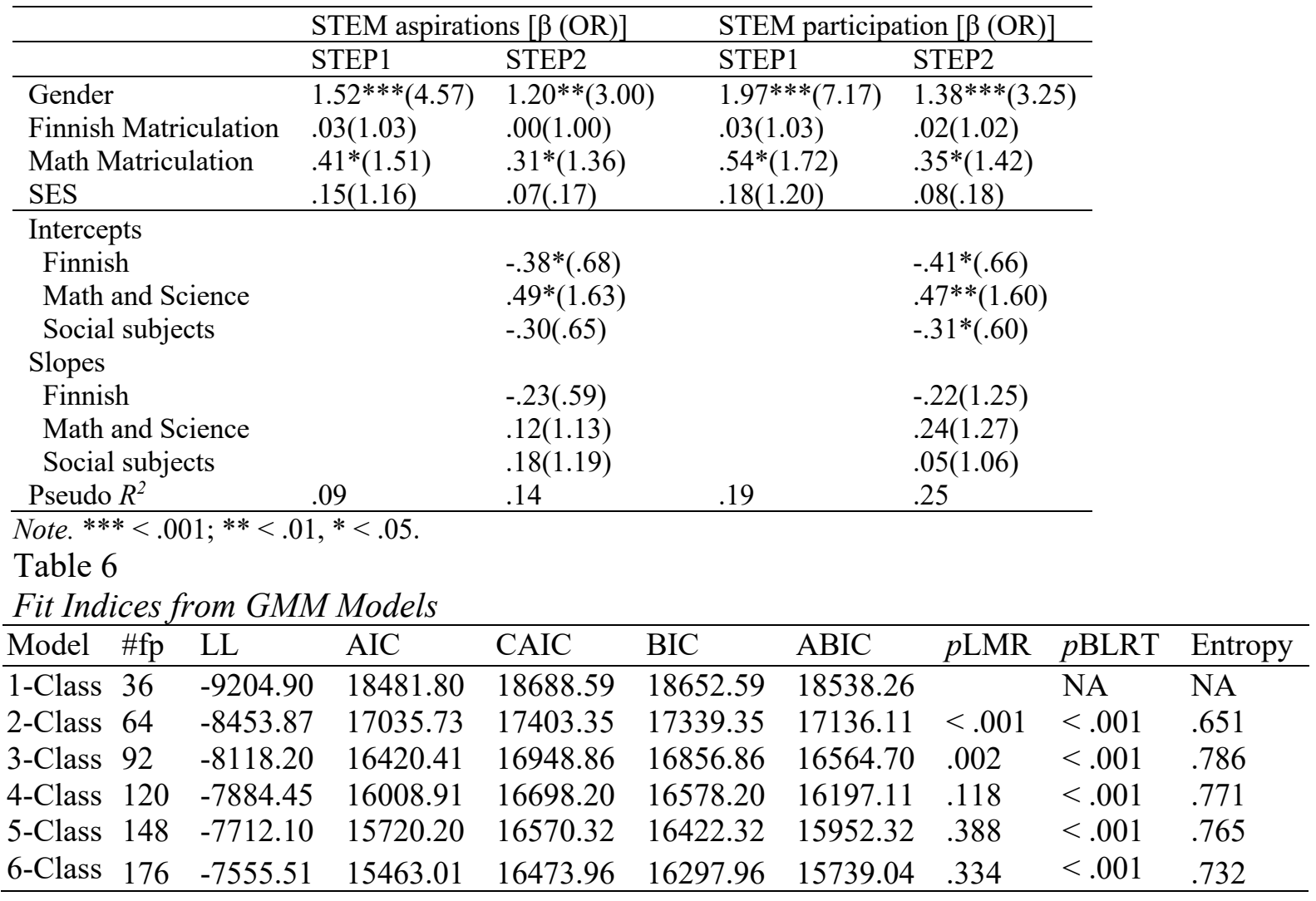

Table 7.

Average Posterior Probabilities (Row) for Most Likely Latent Profile Membership (Column)

\begin{tabular}{cccc}
\hline & $\begin{array}{l}\text { High but Decreasing All } \\
\text { Subjects trajectory }\end{array}$ & $\begin{array}{l}\text { Low but Increasing Math } \\
\text { and Science trajectory }\end{array}$ & $\begin{array}{l}\text { High and Increasing } \\
\text { Finnish trajectory }\end{array}$ \\
\hline 1 & $\mathbf{0 . 8 9}$ & 0.06 & 0.05 \\
2 & 0.07 & $\mathbf{0 . 9 1}$ & 0.02 \\
3 & 0.06 & 0.04 & $\mathbf{0 . 9 0}$ \\
\hline
\end{tabular}


Table 8

Mean and Variance of Intercepts and Slopes across Different Profiles Based on the Unconditional GMM Model

$\mathrm{P} 1(48 \%)$

(High but Decreasing All Subjects)

Intercept

(Mean/Variance)

Finnish

Math and science

Social subjects

Linear slope

(Mean/Variance)

Finnish

Math and science

Social subjects

Note. $* * * .001 ; * *<.01, *<.05$.

$5.31 * * * / .40 * * *$
$5.22 * * * / .27 * * *$
$5.19 * * * / .36 * * *$

$4.22 * * * / .57 * * *$

$4.47 * * * .53 * * *$

$4.28 * * * .55 * * *$
$-.04 / .15^{* *}$
$-.18 * * / .20 * *$
$.03 / .20 * *$
$-.04 * / .05 *$
$.10 * / .20 * *$
$-.02 / .26^{* *}$
$-.12 * * * / .06 *$

P3(19\%)

(High but

Increasing Finnish)

$5.52 * * * / .21 * * *$

$4.84 * * * / .40 * * *$

$5.19^{* * *} / .26^{* * *}$

$.21 * * * / .06 *$

$\mathrm{P} 2(33 \%)$
(Low but Increas
Math and Scienc

$4.22 * * * / .57^{* *}$
$4.47^{* * *} / .53^{* *}$
$4.28^{* * * / .55^{* *}}$

$-.04 / .15^{* *}$
$-.18^{* * / .20 * *}$
$.03 / .20^{* *}$

$5.84^{* * *} / .40^{* * *}$
$5.19^{* * *} / .26^{* * *}$

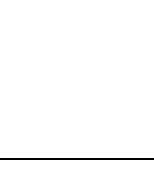


Table 9

Task Value Profile Memberships Predicting STEM Outcomes

\begin{tabular}{|c|c|c|c|c|c|c|}
\hline & \multicolumn{3}{|c|}{ STEM aspirations $[\beta(\mathrm{OR})]$} & \multicolumn{3}{|c|}{ STEM participation $[\beta(\mathrm{OR})]$} \\
\hline & STEP1 & STEP2 & STEP3 & STEP1 & STEP2 & STEP3 \\
\hline Gender & $1.50 * * *(4.48)$ & $1.06^{* * *}(2.89)$ & $.90 * *(2.46)$ & $1.97 * * *(7.17)$ & $1.27 * * *(3.56)$ & $.95 * * *(2.59)$ \\
\hline Finnish Matriculation & $.06(1.06)$ & $.04(1.04)$ & $.02(1.02)$ & $.03(1.03)$ & $.05(1.05)$ & $.01(1.07)$ \\
\hline Math Matriculation & $.39 *(1.48)$ & $.33 *(1.39)$ & $.36 *(1.43)$ & $.54 *(1.72)$ & $36 *(1.43)$ & $.35 *(1.42)$ \\
\hline SES & $.17(1.19)$ & $.13(1.14)$ & $.09(1.09)$ & $.18(1.20)$ & $.17(1.19)$ & $.13(1.14)$ \\
\hline Trajectory profiles & & & & & & \\
\hline $\begin{array}{l}\text { P2(Low but Increasing Math and Science) vs. } \\
\text { P1(High but Decreasing All Subjects) }\end{array}$ & & $.74 * *(2.10)$ & $.71 * *(2.03)$ & & $1.00 * * *(2.72)$ & $.94 * * *(2.56)$ \\
\hline $\begin{array}{l}\text { P3(High but Increasing Finnish) vs. } \\
\text { P1(High but Decreasing All Subjects) }\end{array}$ & & $.12(1.13)$ & $.15(1.16)$ & & $.05(1.05)$ & $.06(1.06)$ \\
\hline $\begin{array}{l}\text { P2(Low but Increasing Math and Science) vs. } \\
\text { P3(High but Increasing Finnish) }\end{array}$ & & $.62 * *(1.86)$ & $.56 * *(1.75)$ & & $.95 * * *(2.59)$ & $.88 * * *(2.41)$ \\
\hline Initial levels (intercepts) of STVs & & & & & & \\
\hline Finnish & & & $-.41 *(.66)$ & & & $-.38 *(.68)$ \\
\hline Math and science & & & $.31 *(1.36)$ & & & $.35 * *(1.42)$ \\
\hline Social subjects & & & $-.03(.97)$ & & & $-.16(.85)$ \\
\hline Pseudo $R^{2}$ & .09 & .19 & .24 & .19 & .27 & .32 \\
\hline
\end{tabular}

Note. $* * *<.001 ; * *<.01, *<.05$.

Table 10

Gender Distribution Across the Three Task Value Trajectories

\begin{tabular}{lllll}
\hline & $\begin{array}{l}\mathrm{P} 1 \\
\text { (High but Decreasing } \\
\text { All Subjects) } \\
\mathrm{N}=408\end{array}$ & $\begin{array}{l}\mathrm{P} 2 \\
\text { (Low but Increasing } \\
\text { Math and Science) } \\
\mathrm{N}=280\end{array}$ & $\begin{array}{l}\text { P3 } \\
\text { (High but } \\
\text { Increasing Finnish) } \\
\mathrm{N}=161\end{array}$ & Mean test between profiles \\
\hline Gender distribution & & & & \\
Females & $200(49 \%)$ & $96(34 \%)$ & $111(69 \%)$ & $47.67^{* * *}$ \\
Males & $208(51 \%)$ & $185(66 \%)$ & $49(21 \%)$ & \\
\hline
\end{tabular}

Note. $* * *<.001$. 
... Finnish - - Math and Science - Social subjects

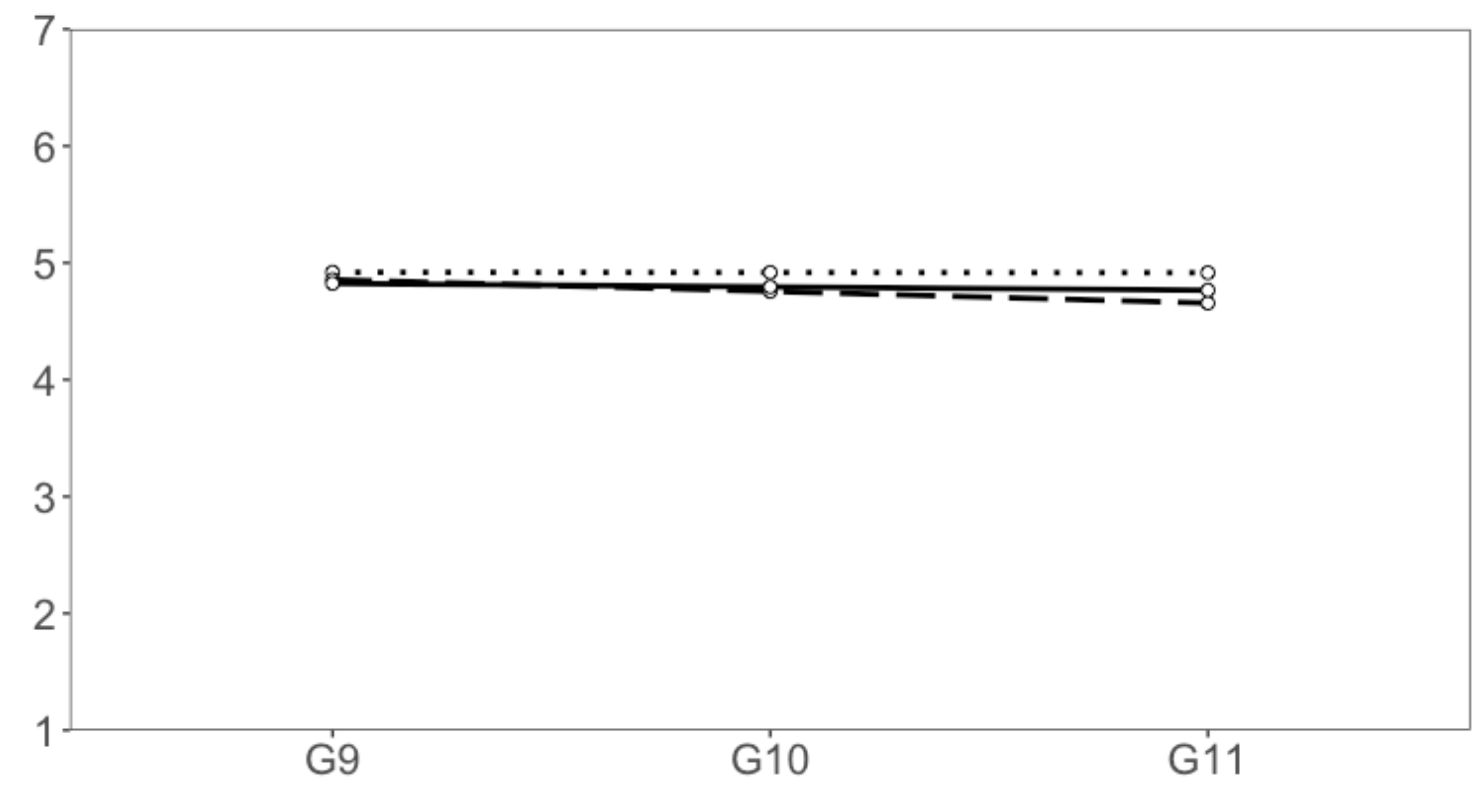

Figure 1. Estimated average trajectories based on the unconditional multivariate LCM (from $9^{\text {th }}$ grade to $11^{\text {th }}$ grade) 


\section{JOINT VALUES TRAJECTORIES}
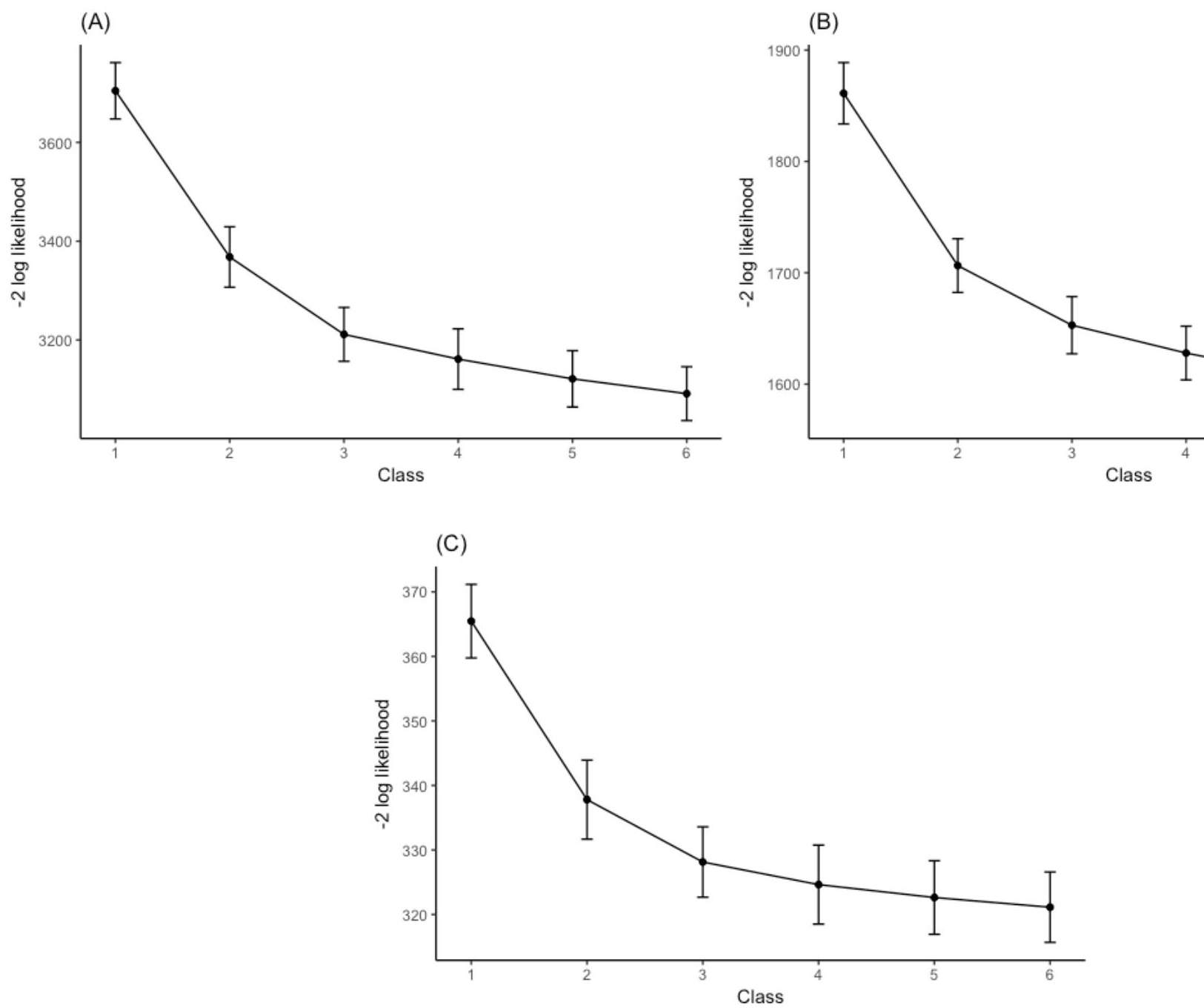

Figure 2. Mean of -2 log likelihood with plus or minus one standard error for the (A) 5-, (B) 10-, and (C) 100-fo number of classes. 
JOINT VALUES TRAJECTORIES

... Finnish - - Math and Science — Social subjects

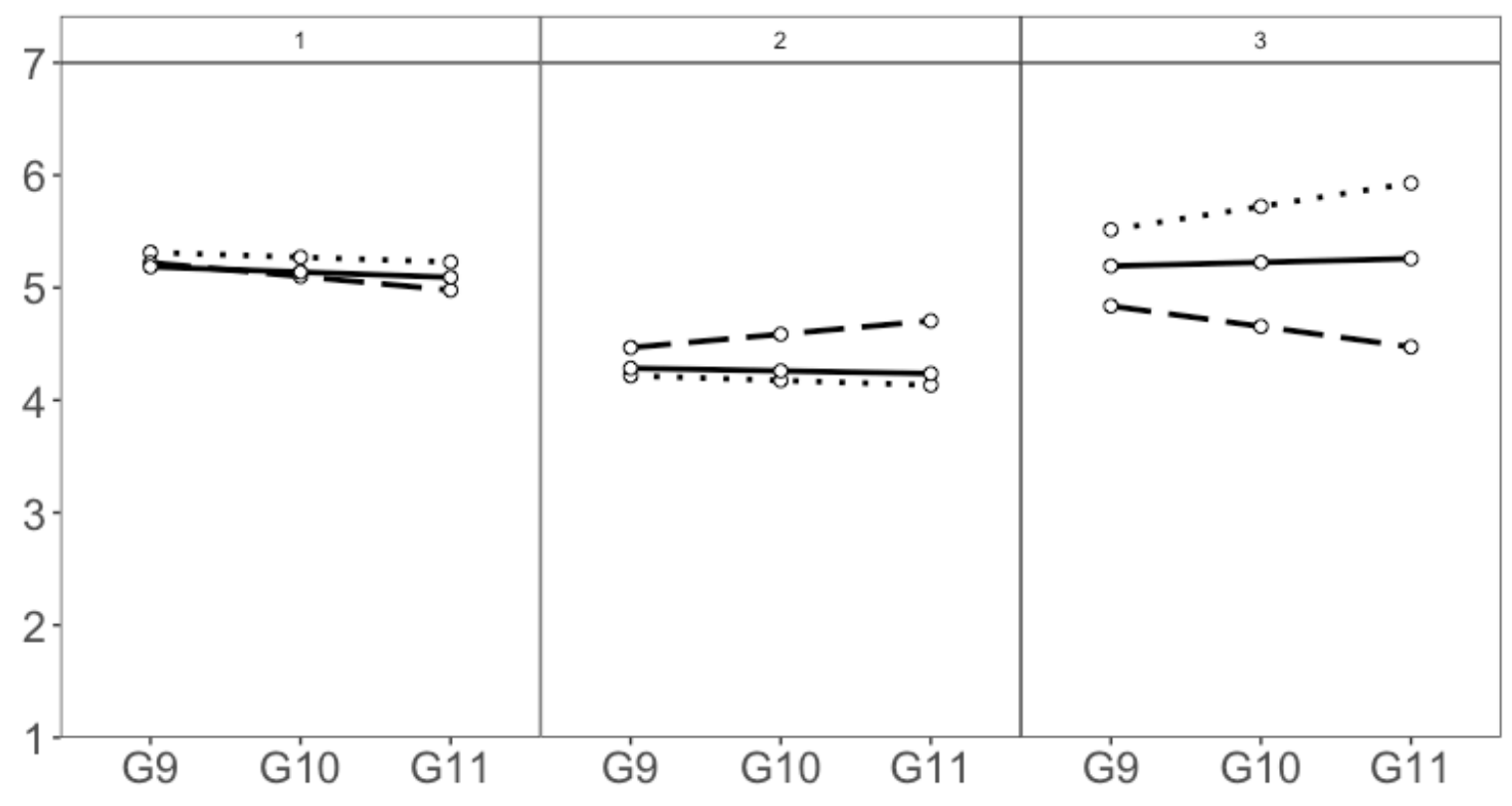

Figure 3. Estimated average trajectories across classes based on the GMM model (from grades 9 to 11). 